\title{
Lusisersily
}

\section{Theoretical and experimental analysis of a horizontal planar Liquid-Vapour Thermal Diode (PLVTD)}

Pugsley, A., Zacharopoulos, A., Mondol, J., \& Smyth, M. (2019). Theoretical and experimental analysis of a horizontal planar Liquid-Vapour Thermal Diode (PLVTD). International Journal of Heat and Mass Transfer, 144, 1-34. [118660]. https://doi.org/10.1016/j.ijheatmasstransfer.2019.118660

Link to publication record in Ulster University Research Portal

\section{Published in:}

International Journal of Heat and Mass Transfer

Publication Status:

Published (in print/issue): 01/12/2019

DOI:

10.1016/j.jheatmasstransfer.2019.118660

\section{Document Version}

Author Accepted version

\section{General rights}

Copyright for the publications made accessible via Ulster University's Research Portal is retained by the author(s) and / or other copyright owners and it is a condition of accessing these publications that users recognise and abide by the legal requirements associated with these rights.

\section{Take down policy}

The Research Portal is Ulster University's institutional repository that provides access to Ulster's research outputs. Every effort has been made to ensure that content in the Research Portal does not infringe any person's rights, or applicable UK laws. If you discover content in the Research Portal that you believe breaches copyright or violates any law, please contact pure-support@ulster.ac.uk. 


\section{Theoretical and experimental analysis of a horizontal}

2 Planar Liquid-Vapour Thermal Diode (PLVTD)

3 Adrian Pugsley (a.pugsley@ulster.ac.uk, +44(0)28 90366264 (corresponding author)

$4 \quad$ Aggelos Zacharopoulos (a.zacharopoulos@ulster.ac.uk) +44(0)2890368227

5 Jayanta Deb Mondol (jd.mondol@ulster.ac.uk) +44(0)28 90368037

6 Mervyn Smyth (m.smyth1@ulster.ac.uk) +44(0)2890368119

Centre for Sustainable Technologies (www.cst.ulster.ac.uk), School of the Built Environment, Ulster University, Newtownabbey, BT37 OQB, Northern Ireland, UK

\section{Keywords}

12 Thermal diode; one-way heat flow; phase change; solar collector; heat rejection

\section{Highlights}

- Horizontal planar unidirectional heat transfer device was realised $\left(0.15 \mathrm{~m}^{2}\right.$ PLVTD)

- Applications in solar collectors and climate control building envelopes

- One-dimensional lumped parameter heat transfer model developed \& interrogated

- Forward mode heat transfer $150<\mathrm{U}_{\mathrm{f}}<500 \mathrm{~W} \cdot \mathrm{m}^{-2} \mathrm{~K}^{-1}$ depends on temperature \& heat flux

- Reverse mode insulation $\mathrm{U}_{\mathrm{r}}=2 \mathrm{~W} \cdot \mathrm{m}^{-2} \mathrm{~K}^{-1}$ achievable using $70 \mathrm{~mm}$ cavity for $97 \%$ diodicity

\section{Abstract}

20 Thermal diodes are unidirectional heat transfer devices, analogous to electrical diodes,

21 which offer low resistance (thermal conductance) in one direction and high resistance

22 (thermal insulation) in the other. Thermal diodicity has significant potential to improve

23 the efficacy of a wide variety of heating and cooling devices. This paper presents

24 pioneering work to experimentally measure the heat transfer characteristics of a

$250.15 \mathrm{~m}^{2}$ passive Planar Liquid-Vapour Thermal Diode (PLVTD). Prior work has typically

26 examined much smaller devices aimed at micro-electronics cooling applications

27 whereas the present work aims to improve understanding of larger scale devices for

28 incorporation in solar collectors and multi-function climate control building envelopes.

29 Such applications can facilitate local renewable energy generation (solar and ambient 30 heat collection) and improve cooling system energy efficiency (passive heat rejection)

31 in order to address the climate crisis by decarbonising built environment energy use.

32 Experimental work involved a horizontally oriented PLVTD formed of two parallel 33 isothermal plates with integral serpentine heat exchangers and external insulation.

34 Plate, fluid, and ambient temperatures were controlled and measured to determine 35 heat transfer coefficients under various temperature difference and heat flux operating 36 scenarios in order to validate a simple one-dimensional lumped parameter model. 
37 Measured forward mode heat transfer $150<\mathrm{U}_{\mathrm{f}}<500 \mathrm{~W} \cdot \mathrm{m}^{-2} \mathrm{~K}^{-1}$ combined with reverse

38 mode insulation $\mathrm{U}_{\mathrm{r}}=10 \mathrm{~W} \cdot \mathrm{m}^{-2} \mathrm{~K}^{-1}$ corresponds $\varsigma \approx 88 \%$ diodicity at low condenser 39 temperatures and fluxes $\left(T_{2} \approx 15^{\circ} \mathrm{C}\right.$ and $\left.\mathrm{q} / \mathrm{A} \approx 120 \mathrm{~W} \cdot \mathrm{m}^{-2}\right)$ and $\varsigma \approx 96 \%$ at high condenser 40 temperatures and heat fluxes $\left(T_{2} \approx 60^{\circ} \mathrm{C}\right.$ and $\left.\mathrm{q} / \mathrm{A} \approx 2800 \mathrm{~W} \cdot \mathrm{m}^{-2}\right)$. Forward mode 41 performance increases with increasing heat flux and (to a lesser extent) with increasing 42 operating temperature but is largely independent of PLVTD dimensions. Reverse mode 43 performance is largely independent of heat flux and temperature but reduces 44 (improves thermal insulation) with increasing cavity depth. The model has been used 45 to show that a stainless steel PLVTD with $\mathrm{x}=70 \mathrm{~mm}$ cavity can achieve $\mathrm{U}_{\mathrm{r}}=2 \mathrm{~W} \cdot \mathrm{m}^{-2} \mathrm{~K}^{-1}$ 46 with similar forward mode performance to the experimental prototype. Such a device 47 would achieve diodicity of $\varsigma>97 \%$ and be suitable for application in solar collectors and 48 climate control building envelopes.

\section{Introduction}

A thermal diode is a unidirectional heat transfer device that operates in a manner analogous to an electrical semiconductor diode by offering low resistance (thermal conductance) in one direction and high resistance (thermal insulation) in the other. The broad concept of a "Thermal diode" and the ideas of "Thermic diodicity" and "Thermal Rectification" have been examined by a number of authors (Go \& Sen, 2010; Roberts \& Walker, 2011; Boreyko et al., 2011; Ben-Abdallah \& Biehs, 2013; Dos Santos Bernardes, 2014; Bairi et al., 2014; Pei et al., 2017). Many of the aforementioned studies relate to thermal rectification using asymmetric solid material conduction, surface radiation, or natural convective thermosyphon arrangements rather than liquid-vapour phase change, but the definitions are equally applicable irrespective of the heat transfer mechanisms involved. A key parameter describing the effectiveness of a thermal diode is its diodicity $(\varsigma)$, for which several definitions are found in the literature. The definition preferred by the present authors is the "diodicity coefficient" which conveniently scales the degree of rectification between zero and unity. Diodicity coefficient (Equation 1 ) is defined in terms of the apparent thermal conductivity $(k)$ of the diode in forward $(f)$ and reverse $(r)$ modes but can alternatively be written in terms of thermal power $(q)$, heat flux $(q / A)$, thermal conductance $(U)$, or thermal resistance $(R)$ where the dimensional quantities $x$ and $A$ relate to the depth and surface area of the diode with $A=y z$ applying in the case of a rectangular flat plate diode of the form shown in Figure 1.

$$
\boldsymbol{\zeta}=\frac{\boldsymbol{k}_{\boldsymbol{f}}-\boldsymbol{k}_{r}}{\boldsymbol{k}_{\boldsymbol{f}}+\boldsymbol{k}_{r}} \quad(0 \geq \varsigma \geq 1)
$$




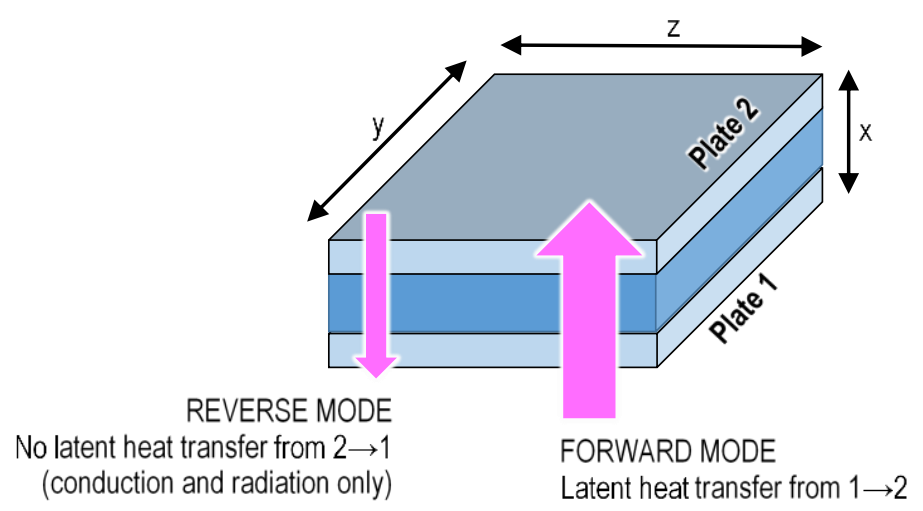

72 Figure 1 - Schematic diagram of a horizontal PLVTD

74 As indicated in Figure 1, a Planar Liquid-Vapour Thermal Diode (PLVTD) realises thermal diodicity by enabling latent transfer (evaporation, vapour mass flow, and condensation) in forward mode and by preventing latent heat transfer in reverse mode.

77 The two operating modes are illustrated in Figure 2 and explained in more detail below.

78 High rates of heat transfer occur during steady state forward mode operation when latent heat transfer processes are enabled because:

- Plate 1 is wetted by the liquid working fluid, and;

- Plate 1 is hotter than Plate 2 and hotter than the working fluid saturation temperature so that evaporation occurs, and;

- Plate 2 is cooler than Plate 1 and cooler than the working fluid saturation temperature so that condensation occurs.

- Working fluid vapour mass flows across the cavity from Plate 1 to Plate 2, primarily driven by the saturation pressure differential, but also in part by natural convection resulting from the density differential and gravity (buoyancy effects).

- Working fluid liquid returns from Plate 2 to Plate 1 . In the simple horizontally oriented PLVTD featured in this study, condensate returns as drips driven by gravity. In PLVTD concepts which operate in vertical or tilted orientations, condensate flow returning to the evaporator must overcome gravity by utilising a capillary wick (Smyth, 2017), mechanical pump (Pugsley et al., 2016), or other driver such as surface wettability gradient (Boreyko and

96 Much lower rates of heat transfer occur during steady state reverse mode operation

97 because Plate 2 is not wetted, meaning that no evaporation can occur, and thus no 
98 latent heat flows between the plates. Residual sensible heat transfer between the 99 plates occurs in reverse mode due to:

- Natural buoyant convection and gaseous conduction associated with working fluid vapour (and non-condensable gases, if present) in the cavity.

- Conductive heat transfer through the diode sidewalls and supporting structure.

- Radiative heat transfer between the two plate surfaces.

104 The PLVTD's diodicity relies upon ensuring that the working fluid circulation 105 arrangement continually wets Plate 1 in forward mode and enables Plate 2 to remain 106 dry in reverse mode. Inadvertent wetting of Plate 2 during reverse mode operation will 107 facilitate latent heat transfer that will undermine the insulation performance and 108 significantly diminish the diodicity.

109

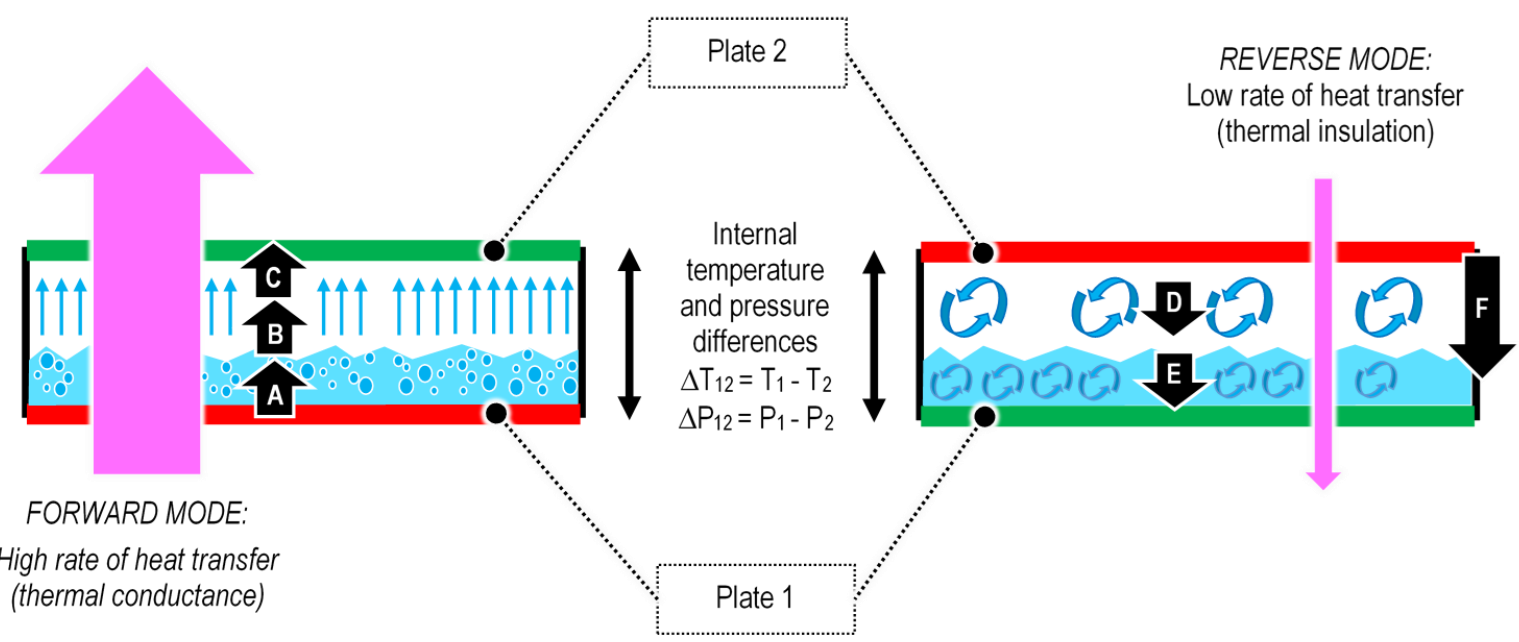

\section{Key to annotations}

A) Evaporation of the working fluid due to heat input at temperature $T_{1}$

B) Working fluid vapour mass transfer across cavity due to pressure difference $\Delta P_{12}=P_{1}-P_{2}$. The working fluid exists in a condition close to the liquid-vapour saturation point. The average vapour pressure $\left(P_{L v}\right)$ corresponds to the saturation temperature ( $\left.T_{L V}\right)$ which is approximately equal to the average operating temperature $T_{12}=\left(T_{1}+T_{2}\right) / 2$

C) Condensation of the working fluid produces heat output at temperature $T_{2}$

D) Buoyancy induced working fluid vapour convection due to temperature difference $\Delta T_{12}=T_{1}-T_{2}$

E) Buoyancy induced working fluid liquid convection

F) Residual heat transfer via radiation between plates and conduction through sidewalls and structural elements 
113 Thermal diodes are well suited to electronics cooling applications (Boreyko and Chen, 1142011 \& 2013; Chen et al., 2012; Blet et al., 2017; Avanessian and Hwang, 2018; 115 Traipattanakul et al., 2019; Wong et al., 2019), solar collector applications (De Beijer, 116 1998; Quinlan, 2010; Souliotis et al., 2011\&2017; Smyth et al., 2015a\&b, 2017, 2018, 117 2019; Pugsley et al., 2016; Pugsley, 2017; Muhumuza et al., 2019a \& b), climate 118 control building envelopes (Chen et al., 1998; Varga, 2002; Reay et al., 2014; 119 Villeneuve et al., 2017), and permafrost stabilisation applications (Pan and Wu, 2002; 120 Pei et al., 2017). Applications in spacecraft (Gaddam and Huxtable, 2017) and caloric 121 refrigeration systems (Hess et al., 2019), and thermal computing (Tso and Chao, 2016; 122 Shen et al., 2018) have also been proposed. The majority of extant published work on 123 liquid-vapour phase change thermal diodes relates to either axial devices (eg heat 124 pipes), annular devices (eg cylindrical or elliptical tanks), or small planar devices (eg 125 jumping drop diodes).

126 Wong et al. (2019) examined an axial liquid-vapour thermal diode with small circular 127 heat transfer plates (equal evaporator and condenser areas $A_{e}=A_{c}=0.01 \mathrm{~m}^{2}$ ) oriented 128 horizontally and separated by a relatively large cavity $(x=76 \mathrm{~mm})$. The device is 129 superficially similar to a wickless heat pipe, and essentially similar to the PLVTD 130 described in Figures 1 and 2, relying upon gravity to induce the return flow of 131 condensate from the condenser to the evaporator pool. Tests demonstrated that the 132 device achieved forward and reverse mode thermal conductances of $\mathrm{U}_{\mathrm{f}} \approx 40 \mathrm{~W} \cdot \mathrm{m}^{-2} \mathrm{~K}^{-1}$ 133 and $\mathrm{U}_{\mathrm{r}} \approx 16 \mathrm{~W} \cdot \mathrm{m}^{-2} \mathrm{~K}^{-1}$ corresponding to diodicity of $\varsigma \approx 43 \%$. Reverse mode heat transfer 134 appears to be mainly governed by conduction whereas forward mode heat transfer is 135 governed by buoyant natural convection (thermosyphonic action of air and water) and 136 boosted by liquid-vapour-liquid phase change (latent heat transfer).

137 Smyth et al. (2017 \& 2018) and Muhumuza et al. (2019a \& b) examined various 138 cylindrical solar water heaters featuring annular liquid-vapour thermal diodes. Early 139 prototypes were oriented vertically whilst more recent evolutions have been horizontal 140 such that the thermal diode operates broadly similarly to Figure 3a with condensate 141 return via gravity. According to Quinlan (2010), Smyth et al. (2017) and Pugsley 142 (2017), the "Mark IV" was formed of a 300mm diameter, 1000mm long, cylindrical 143 outer vessel and a $200 \mathrm{~mm}$ diameter, $900 \mathrm{~mm}$ long, inner vessel arranged concentrically 144 to form an annulus cavity of $x=50 \mathrm{~mm}$. During heat collection (forward mode) wetted 145 pockets on the inner surface of the outer vessel act as evaporators $\left(A_{e} \approx 0.5 \mathrm{~m}^{2}\right)$ 146 transferring latent heat in the form of vapour which condenses on the outer surface of 147 the inner vessel $\left(A_{c} \approx 0.6 \mathrm{~m}^{2}\right)$. During heat retention (reverse mode) the annulus acts 148 as an insulator because the outer surface of the inner vessel is kept dry. Test results 149 showed that the annular thermal diode achieved forward and reverse mode heat 150 transfer $U_{f} A \approx 13 \mathrm{~W} \cdot \mathrm{K}^{-1}$ and $U_{\mathrm{r}} \mathrm{A} \approx 1.3 \mathrm{~W} \cdot \mathrm{K}^{-1}$ corresponding to diodicity of $\varsigma \approx 82 \%$. 
151 Comprehensive work on planar liquid-vapour thermal diodes was undertaken by

152 Boreyko and Chen (2011 \& 2013) who developed, tested and modelled a PLVTD of

153 similar form to that illustrated in Figures 1 and 2. A key innovation in their device was

154 the use of a superhydrophobic condenser and a superhydrophilic wicked evaporator to

155 enable the working fluid to return from the condenser to the evaporator via the

156 "jumping drop" phenomenon. This feature gave the device gravity-independent

157 operation enabling it to function in any orientation (horizontal, vertical or tilted) which

158 is important for its primary application in mobile electronic devices, but also relevant

159 to solar collectors and building envelopes. Experimental work utilised a small prototype

160 consisting of two square copper plates $\left(A_{e}=A_{c}=0.006 \mathrm{~m}^{2}\right)$ separated by an EPDM gasket

161 (various thicknesses up to $x=4 \mathrm{~mm}$ ) and achieved forward and reverse mode thermal

162 conductances of $\mathrm{U}_{\mathrm{f}}=40500 \mathrm{~W} \cdot \mathrm{m}^{-2} \mathrm{~K}^{-1}$ and $\mathrm{U}_{\mathrm{r}}=165 \mathrm{~W} \cdot \mathrm{m}^{-2} \mathrm{~K}^{-1}$ corresponding to diodicity

163 of $s=99 \%$. Using a similar but smaller device $\left(A_{e}=A_{c}=0.0012 m^{2}\right)$, Traipattanakul et al.

164 (2019) explored the possibility of using an electric field to enable jumping drop action

165 across a wider separation of the diode plates $(x=7 \mathrm{~mm})$ to enable lower reverse mode

166 performances. The work successfully proved the concept, but the relatively small plate-

167 to-plate cavity width $(x)$ limited the overall thermal insulation values to only

$168 \sim 10 \mathrm{~W} \cdot \mathrm{m}^{-2} \mathrm{~K}^{-1}$ which is an order of magnitude greater than typically required for solar

169 collector and building envelope applications.

170 All of the abovementioned experimental studies used water as the working fluid to

171 facilitate the latent heat transfer, and with the exception of the work by Wong et al.

172 (2019), all utilised cavity evacuation to remove non-condensable gases and facilitate

173 low temperature evaporation of water at sub-atmospheric pressures. Boreyko and

174 Chen (2013) demonstrated clearly that forward mode heat transfer is maximized when

175 non-condensable gases are removed such that the cavity pressure approaches the

176 saturation pressure of the working fluid.

177 The most basic realization of a PLVTD is the horizontally oriented form shown in

178 Figure 2 whereby Plate 1 is permanently wetted by a pool of liquid working fluid which

179 covers the evaporator surface. Condensate forms on Plate 2 when forward mode heat

180 transfer occurs and this liquid flows back to Plate 1 due to gravity so that operation

181 can continue indefinitely. This form of PLVTD could feasibly be used as a heat transfer

182 element in a concentrating solar water heater (see Figure 3a) or as a flat roofing panel

183 for buildings in hot climates where daytime solar gain control and night-time free-

184 cooling are required (see Figure $3 \mathrm{~b}$ ). 
185 The study presented in this paper aims to build upon the aforementioned studies by 186 improving understanding of large scale PLVTDs. Prior work on PLVTDs has generally 187 been focussed on small devices with evaporator and condenser plate areas of $188 \mathrm{~A} \leq 0.01 \mathrm{~m}^{2}$ and cavity depths of $\mathrm{x} \leq 7 \mathrm{~mm}$ which, whilst relevant to micro-electronics 189 cooling applications, are of limited direct relevance to solar collector and multi-function 190 climate control building envelope applications. Prior work on larger scale thermal 191 diodes has generally focussed on devices with inherently axial or annual forms which 192 differ significantly from the flat plate form of a true PLVTD. This study describes 193 pioneering work to experimentally measure the heat transfer characteristics of a $1940.15 \mathrm{~m}^{2}$ PLVTD under various realistic operating conditions and presents a 195 corresponding validated one-dimensional lumped parameter heat transfer model.

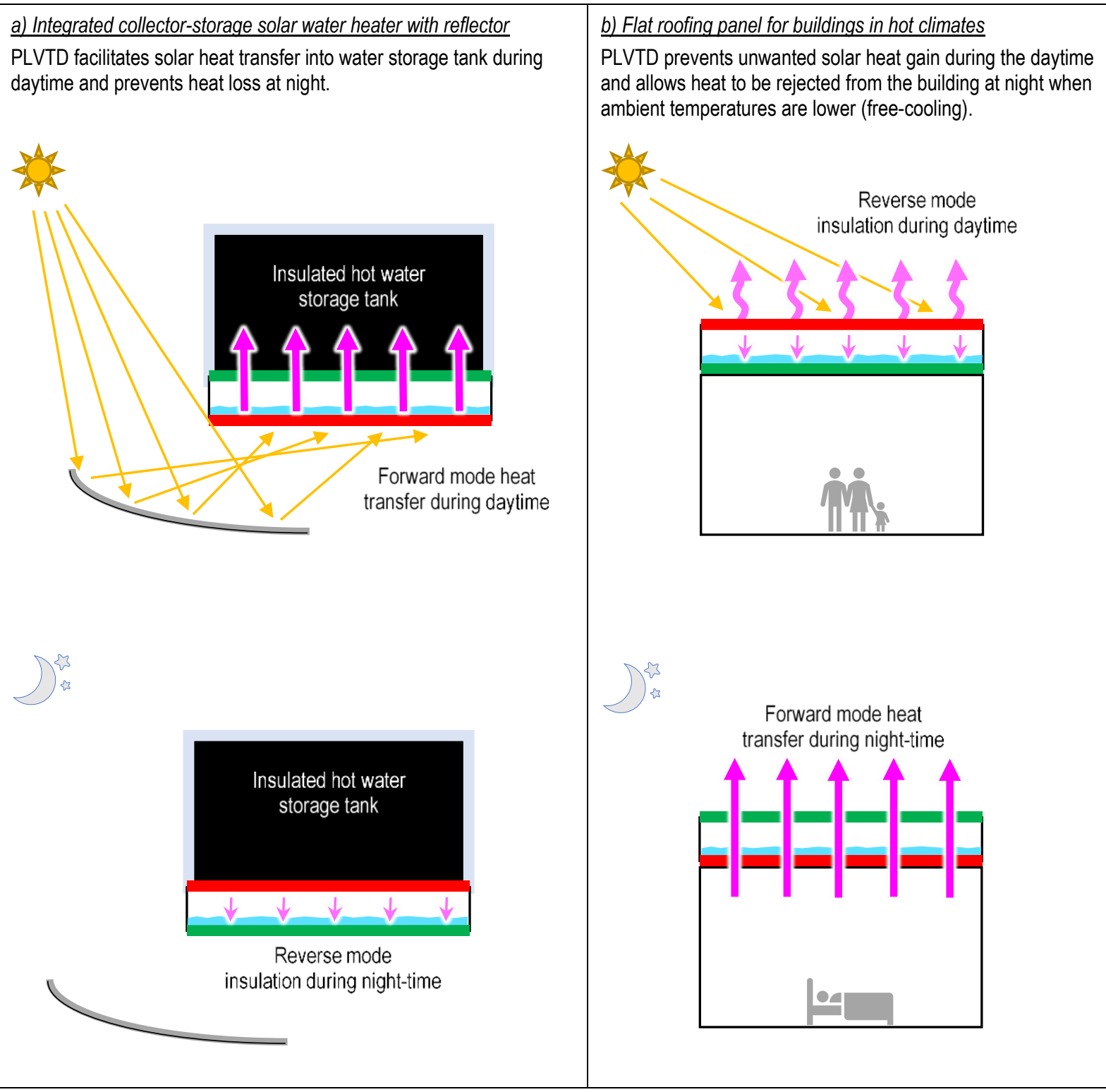

Figure 3 - Practical applications for a horizontal PLVTD 


\subsection{Heat flux, temperature and pressure}

201 Heat transfer is driven by the difference in temperature between the two plates $\left(\Delta T_{12}\right)$.

202 The transferred thermal power $\left(q_{12}\right)$, transferred heat flux $\left(q_{12} / A_{p}\right)$, overall thermal 203 resistance $\left(\mathrm{R}_{\mathrm{fr}}\right)$, and overall thermal conductance $\left(\mathrm{U}_{\mathrm{fr}}\right)$ through the PLVTD are related 204 according to Equation 2. Figure 4 shows the main heat transfer paths and 205 corresponding thermal resistances through a PLVTD in both forward and reverse mode.

$$
U_{f r}=\frac{q_{12}}{y z\left(T_{1}-T_{2}\right)}=\frac{q_{12}}{A_{p} \Delta T_{12}}=\frac{1}{A_{p} R_{f r}}
$$

Equation 2

207 In forward mode, the dominant thermal transmission mechanism is latent heat transfer 208 associated with working fluid liquid-vapour-liquid phase changes and the net transfer 209 of working fluid vapour mass across the cavity between the two plates. In reverse 210 mode, thermal transmission occurs via several different mechanisms including working 211 fluid natural convection (vapour and liquid without phase change), radiation across the 212 cavity, and conduction through the envelope and supporting structural elements, but 213 no latent heat transfer occurs. In order to transfer heat in forward mode the working 214 fluid must exist in vapour phase at the evaporator temperature $\left(T_{1}\right)$ and in liquid phase 215 at the condenser temperature $\left(T_{2}\right)$. If all non-condensable gases are removed, then 216 the resulting pressure inside the PLVTD will be approximately equal to the saturation 217 pressure $\left(P_{L v}\right)$ of the working fluid at the average operating temperature $218 \mathrm{~T}_{12}=\left(\mathrm{T}_{1}+\mathrm{T}_{2}\right) / 2$. This internal pressure will usually be different from the atmospheric 219 pressure outside necessitating internal structures to ensure that the PLVTD envelope 220 can withstand the pressure differential (hence need for supporting structure). Thermal resistance lumped parameter model

222 The total thermal resistance associated with latent heat transport ( $\left.R_{L v L}\right)$ through the 223 working fluid can be defined as the sum of individual evaporation $\left(R_{e}\right)$, vapour mass 224 flow $\left(R_{e c}\right)$, and condensation $\left(R_{c}\right)$ components acting in series. Thermal resistance $R_{L v L}$ 225 is inherently much lower than the sum of the series thermal resistances associated 226 with sensible heat transport through the working fluid in its liquid $\left(R_{L}\right)$ and vapour $\left(R_{v}\right)$ 227 forms (ie natural convection without phase change). Thermal resistances associated 228 with conduction through the two plates $\left(2 R_{p}\right)$ act in series with the aforementioned 229 components, whereas thermal resistances associated with radiation between the plates $230\left(R_{R}\right)$, conduction through the sidewalls $\left(R_{w}\right)$, and conduction through structural support 231 elements $\left(R_{S}\right)$ act in parallel. Inspection of the resulting thermal resistance network in 232 Figure $4 \mathrm{c}$ suggests that the overall thermal resistance through the PLVTD during 233 forward mode operation $\left(\mathrm{R}_{\mathrm{f}}\right)$ can be approximated by Equation 3 . 

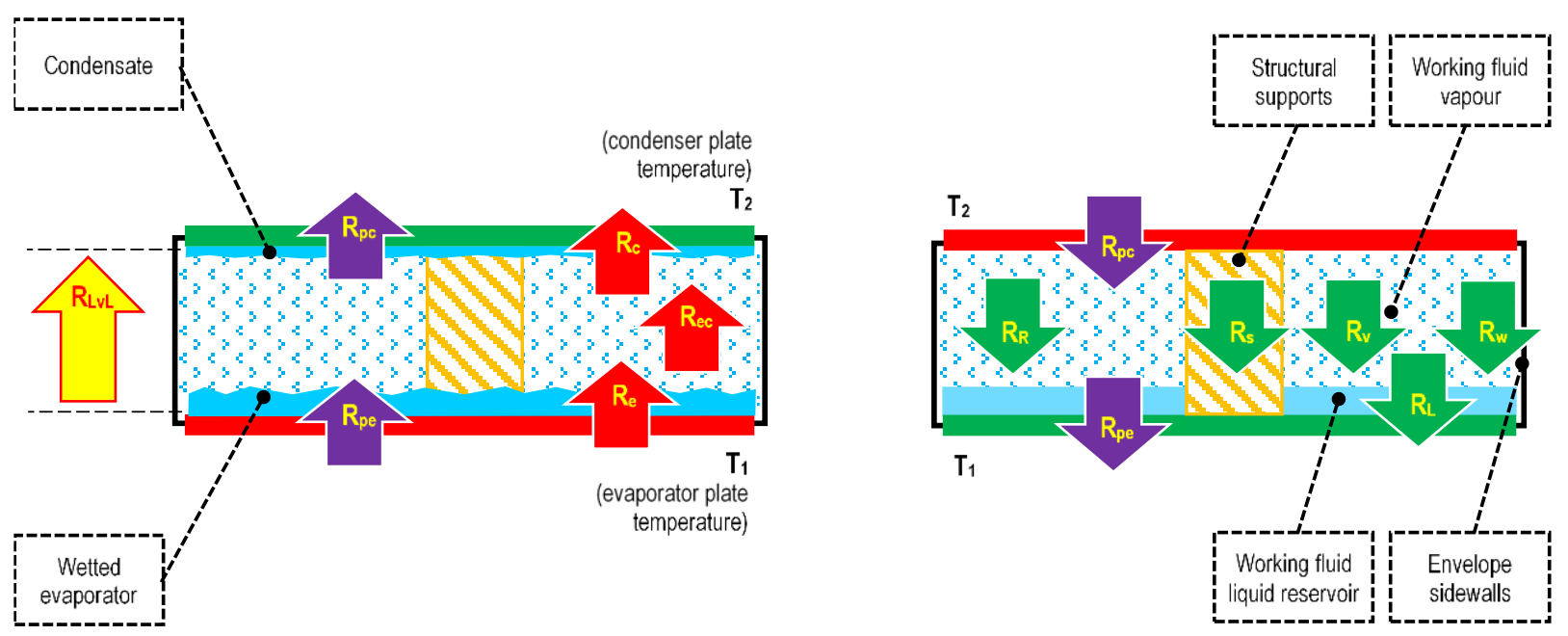

c) Thermal resistance network describing heat transfer behaviour

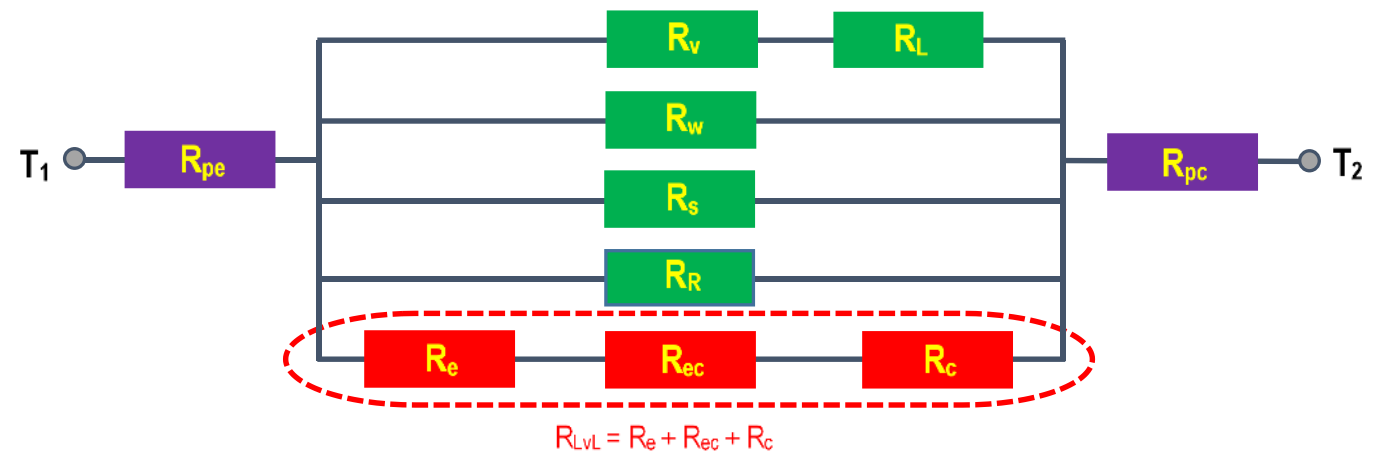

d) Descriptions of thermal resistances used in the model

$\mathrm{R}_{\mathrm{pe}} \quad$ Conductive thermal resistance through the plate which acts as the evaporator in forward mode

$R_{p c} \quad$ Conductive thermal resistance through the plate which acts as the condenser in forward mode

$R \quad$ Resistance associated with working fluid evaporation occurring at the evaporator surface

$\mathrm{R}_{\mathrm{c}} \quad$ Resistance associated with working fluid condensation occurring at the condenser surface

$\mathrm{R}_{\mathrm{ec}} \quad$ Mass transfer resistance associated with the flow of vapour from the evaporator to the condenser

$\mathrm{R}_{\mathrm{LvL}} \quad$ Overall Liquid-vapour-Liquid phase change heat transfer resistance
$R_{w} \quad$ Conductive thermal resistance through four sidewalls forming the PLVTD envelope

$\mathrm{R}_{\mathrm{S}} \quad$ Conductive thermal resistance through the structural members which support the PLVTD envelope

$R_{v} \quad$ Resistance associated with vapour phase natural convection of the working fluid

$R_{L} \quad$ Resistance associated with Liquid phase natural convection of the working fluid

$R_{R} \quad$ Resistance associated with heat transfer via long wave electromagnetic radiation between the two plates 
238 The evaporator plate is dry in reverse mode so that the latent heat transport thermal 239 resistances tend towards infinity and $1 /\left(R_{e}+R_{e c}+R_{c}\right) \rightarrow 0$. Inspection of the thermal 240 resistance network then yields Equation 4 to describe the overall thermal resistance

241 through the PLVTD during reverse mode operation $\left(R_{r}\right)$.

$$
R_{f}=1 /\left(\frac{1}{R_{e}+R_{e c}+R_{c}}+\frac{1}{R_{w}}+\frac{1}{R_{S}}+\frac{1}{R_{R}}\right)+2 R_{p}
$$

Equation 3

$$
R_{r}=1 /\left(\frac{1}{R_{L}+R_{v}}+\frac{1}{R_{w}}+\frac{1}{R_{s}}+\frac{1}{R_{R}}\right)+2 R_{p}
$$

Equation 4

\subsection{Envelope, structure, and radiation thermal resistances}

245 The envelope and structure thermal resistances can be evaluated using conventional

246 Fourier methods. Assuming that the PLVTD envelope is of a basic rectangular box form

247 (as per Figure 1) and the internal supporting structure is an array of cylindrical struts

248 similar to that used in vacuum glazing panels (Collins and Fischer-Cripps, 1991; Fang

249 et al., 2014) the thermal conductances and corresponding resistances of the 250 evaporator and condenser plates $\left(U_{p e} \approx U_{p c}\right)$, the envelope sidewalls $\left(U_{w}\right)$, and the 251 supporting structure $\left(U_{S}\right)$, can be evaluated according to Equations 5 to 9. The 252 nomenclature used for the various dimensional terms are defined in full in Section 9.

253 The symbols $U, R, k, A$ and d refer to thermal conductance, thermal resistance, thermal 254 conductivity, area and distance respectively. The symbols and subscripts $\mathrm{x}, \mathrm{y}, \mathrm{z}$ refer 255 to dimensions in the respective axes defined on Figure 1. The subscripts $p, w$, and $s$ 256 relate to the plate, wall and struts respectively. The term $\mathrm{N}_{s}$ refers to the number of 257 struts in the internal supporting structural array where each strut is assumed to be a 258 cylindrical tube with diameter $d_{s}$, wall thickness $d_{s w}$, and approximate length $x$. The 259 term $d_{s s}$ refers to the centre-to-centre spacing between adjacent struts and the terms $260 d_{s x y}$ and $d_{s x z}$ refer to spacings between struts and adjacent sidewalls.

$$
U_{p}=\frac{1}{A_{p} R_{p}}=\frac{k_{p}}{x_{p}}
$$

$$
U_{w}=\frac{1}{A_{p} R_{w}}=\frac{2 z_{w}\left(y+z-2 z_{w}\right) k_{w}}{x y z}
$$

$$
U_{s}=\frac{1}{A_{p} R_{S}}=\frac{N_{s} A_{s} k_{S}}{x y z}
$$

$$
A_{s}=\pi\left(\frac{d_{s}}{2}\right)^{2}-\pi\left(\frac{d_{s}-2 d_{s w}}{2}\right)^{2}
$$

$$
N_{s}=\left(\frac{y-2 d_{s x y}}{d_{s s}}+1\right)\left(\frac{z-2 d_{s x z}}{d_{s s}}+1\right)=\left(\frac{y-x}{d_{s s}}+1\right)\left(\frac{z-x}{d_{s s}}+1\right)
$$


Radiative heat transfer resistance between the two parallel plates can be determined using Equation 10 (Twidell \& Weir, 2006) based on the PLVTD absolute operating temperatures in Kelvin degrees $\left(T_{12}\right)$, emissivities of the wet or dry plates $\left(\varepsilon_{1}\right.$ and $\left.\varepsilon_{2}\right)$, the Stefan-Boltzmann constant $\left(\chi=5.67 \times 10^{-8} \mathrm{~W} \cdot \mathrm{m}^{-2} \mathrm{~K}^{-4}\right)$ and the area over which radiative heat exchange occurs ( $A \approx A p$, assuming negligible wall thicknesses).

$$
R_{R}=\frac{1 / \varepsilon_{1}+1 / \varepsilon_{2}-1}{4 \chi A\left(T_{12}\right)^{3}}
$$

Equation 10

\subsection{Evaporation, condensation and working fluid mass flow}

Heat transfer through the PLVTD via the working fluid is dependent upon a number of different mechanisms:

- Sensible heat transfer via buoyancy driven natural convection of the working fluid, in both vapour $\left(R_{\mathrm{v}}\right)$ and liquid $\left(R_{\mathrm{L}}\right)$ states, in reverse mode, due to plateto-plate temperature differential $\Delta T_{12}$.

- Working fluid evaporation $\left(R_{e}\right)$ in forward mode.

- Latent heat transfer due to net vapour mass flow between the plates in forward mode $\left(R_{e c}\right)$. Fluid motion is primarily driven by the vapour pressure differential $\left(\Delta \mathrm{P}_{12}\right.$ arising from $\Delta \mathrm{T}_{12}$ ) and to a lesser extent by corresponding buoyancy forces.

- Working fluid condensation $\left(R_{c}\right)$ in forward mode.

Working fluid thermal resistances and corresponding conductances can be evaluated using Equation 11 from appropriate Nusselt number correlations $(\mathrm{Nu})$, characteristic dimensions $(L)$ and working fluid thermal conductivities $(k)$.

$$
R=\frac{1}{A_{p} U}=\frac{L}{A_{p} k N u}
$$

287 For sensible convective heat transfer through vapour within a horizontal PLVTD of the 288 form shown in Figure 2 (relevant to evaluation of $R_{v}$ ) the Nusselt number is 289 approximately $\mathrm{Nu} \approx 1$ during reverse mode operation because the hot surface is at the 290 top of the cavity. The characteristic dimension is approximately equal to the cavity 291 depth $(L \approx X)$.

292 For sensible convective heat transfer through liquid within a horizontal PLVTD (relevant 293 to evaluation of $R_{e}$ and $R_{L}$ ) the Nusselt number can be evaluated using Equations 12 294 to 14 depending upon Rayleigh number and operating mode. Rayleigh numbers are 295 typically evaluated using Equation 15 which accounts for buoyancy and frictional 
296 effects based upon gravitational acceleration ( $g=9.81 \mathrm{~m} / \mathrm{s}^{2}$ at sea level), plate-to-liquid 297 temperature difference $\left(\Delta \mathrm{T}_{\mathrm{L} 1}=\mathrm{T}_{1}-\mathrm{T}_{12}\right)$ and temperature dependent working fluid 298 thermodynamic properties including kinematic viscosity (v), Prandtl number (Pr) and 299 volumetric expansion coefficient $(\beta)$ which should be evaluated at the liquid 300 temperature $T_{L 1}=\left(T_{1}+T_{12}\right) / 2$. The characteristic dimension is defined as the ratio of the 301 plate area divided by the plate perimeter length according to Equation 16. In solar 302 collector and climate control building envelope applications, the vaporisation process 303 during forward mode occurs primarily as a result of free-surface evaporation because 304 heat fluxes are low and resulting plate-to-liquid temperature differences are not large 305 enough to facilitate nucleate boiling. Equations suited to modelling high heat flux 306 operating scenarios and alternative PLVTD orientations (vertical, tilted, and inverted) 307 are given by Pugsley (2017) but have been omitted here for brevity.

308

309

310

For latent heat transfer caused by vapour mass flow and vapour convection during 314 forward mode operation (relevant to evaluation of $R_{e c}$ ) the Nusselt number can be 315 evaluated using Equation 17 (Cengel, 2006) which is appropriate to rectangular 316 enclosures where the hot surface is at the bottom of the cavity and is valid for Prandtl 317 numbers $0.1<\operatorname{Pr}<10$ and Rayleigh numbers $\operatorname{Ra}<10^{8}$. Whilst the Rayleigh number for 318 sensible heat transfer is determined by considering buoyancy as the driving force 319 (Equation 17), for latent heat transfer in forward mode, the Rayleigh number is 320 additionally dependent upon the vapour pressure differential $\Delta P_{12}=\left|P_{1}-P_{2}\right|$ associated 321 with the plate-to-plate temperature difference $\Delta T_{12}=\left|T_{1}-T_{2}\right|$. This phase change 322 pressure differential provides the dominant driving force which, in addition to buoyancy 323 force, overcomes the viscous and frictional forces associated with vapour convection. 324 Methods for determining modified Rayleigh ( $\mathrm{Ra}^{*}$ ) numbers appropriate for evaluating 325 vapour mass transfer thermal resistance in phase change scenarios (both with and 326 without non-condensable gases present) were proposed by Pugsley (2017) drawing on 327 the work of Stein et al. (1985) and Peterson (1996). Equations 18 to 20 can be used 
328 in cases where all non-condensable gases have been removed such that the PLVTD

329 cavity exists at the working fluid saturation pressure $\left(P_{L V}\right)$ corresponding to the average 330 temperature $T_{12}=\left(T_{1}+T_{2}\right) / 2$. The terms $h_{L v}, \vartheta, \mathcal{M}$, and $\mathcal{R}$ are the latent heat of phase 331 change, thermal diffusivity, working fluid molar mass, and universal gas constant 332 respectively. All thermodynamic properties in Equations 18 to $20(\mathrm{k}, \mathrm{v}, \vartheta, \beta, \rho)$ relate 333 to the vapour state which exists at a temperature close to that of the average of the 334 two plates $\left(T_{v} \approx T_{12}\right)$. In the case of vapour flowing due to phase changes, the effective 335 thermal conductivity ( $k$ of Equation 11 ) has both sensible vapour $\left(k_{v}\right)$ and latent $\left(k_{L v}\right)$ 336 components which can be quantified using Equation 19 and 20.

$$
N u=1+1.44\left[1-\frac{1708}{R a}\right]^{+}+\left[\frac{R a^{1 / 3}}{18}-1\right]^{+}
$$

Equation 17

$$
\begin{aligned}
& R a^{*}=\frac{\left[\frac{P_{L v}}{\rho L}+g\right] \beta \Delta T_{12} L^{3}}{v^{2}} P r \\
& k=k_{v}+k_{L v} \\
& k_{L v}=\frac{h_{L v}{ }^{2} P_{L v} \mathcal{M}^{2} \vartheta}{\mathcal{R}^{2} T_{12}{ }^{3}}
\end{aligned}
$$$$
\text { Equation } 18
$$$$
\text { Equation } 19
$$

341 Heat transfer due to condensation on the underside of the top plate during forward

342 mode operation (relevant to evaluation of $R_{c}$ ) can be evaluated using Equations 21 and

34322 which are based on expressions given by Gerstmann \& Griffith (1967) and by Stein 344 et al. (1985). The difference in the liquid and vapour densities ( $\rho\left\llcorner\right.$ and $\rho_{v}$ ) plays an 345 important role in both expressions alongside the liquid kinematic viscosity ( $\left.\mathrm{V}_{\mathrm{L}}\right)$, surface 346 tension $\left(\sigma_{\mathrm{L}}\right)$, and thermal conductivity $\left(\mathrm{k}_{\mathrm{L}}\right)$. Vapour thermodynamic properties and 347 saturation condition thermodynamic properties can be evaluated at the estimated 348 saturation temperature $\left(\mathrm{T}_{\mathrm{LV}} \approx \mathrm{T}_{12}\right)$. Liquid condensate thermodynamic properties can be 349 evaluated at the estimated condensate film temperature $T_{L 2}=\left(T_{12}+T_{2}\right) / 2$.

$$
R a=\frac{g\left(\rho_{L}-\rho_{v}\right) h_{L v}\left(\frac{\sigma_{L}}{g\left(\rho_{L}-\rho_{v}\right)}\right)^{1.5}}{k_{L} v_{L}\left(T_{L v}-T_{2}\right)}
$$

$$
R_{C}=\frac{\left(\frac{\sigma_{L}}{g\left(\rho_{L}-\rho_{v}\right)}\right)^{0.5}}{A_{p} k_{L} 0.69 R a^{0.2}}
$$


354 The experimental methodology largely followed the precedent set by the work of 355 Boreyko \& Chen (2013) but using apparatus with larger plate area dimensions (to 356 better reflect the sizes of relevance to solar collector and climate control building 357 envelope applications) and without special treatments to the evaporator or condenser 358 surfaces (aluminium plates with standard mill finish). Steady state temperatures and 359 heat fluxes were achieved by circulating heated and chilled water through channels 360 located within the body of the evaporator and condenser plates. The specific objectives 361 of the experimental investigation were to quantify the effects of varying the:

- Reverse mode plate-to-plate temperature differential in the range $5<\Delta \mathrm{T}_{12}<70^{\circ} \mathrm{C}$ corresponding to nominal plate temperatures of $20<\mathrm{T}_{2}<75^{\circ} \mathrm{C}$ and $5<\mathrm{T}_{1}<15^{\circ} \mathrm{C}$.

- Forward mode heat fluxes in the range $100<\mathrm{q} / \mathrm{A}<6000 \mathrm{~W} \cdot \mathrm{m}^{-2}$ corresponding approximately to plate-to-plate temperature differences of $1<\Delta \mathrm{T}_{12}<10^{\circ} \mathrm{C}$.

Photographs of the PLVTD used for the experimental investigation are shown on Figures 5 and 6 . The key components included:

- Spacer frame (A) acted as the sidewalls forming the PLVTD cavity. Several different spacer frames were fabricated using a CNC controlled water-jet cutting machine. Test results presented in this paper were undertaken using an $11 \mathrm{~mm}$ thick nylon spacer which was found to provide superior reverse mode (insulation) performance owing to its low thermal conductivity.

- Two heat transfer plates (B1 \& B2) which acted as the evaporator and condenser, each consisting of a $300 \times 500 \mathrm{~mm}$ piece of $12 \mathrm{~mm}$ thick aluminium plate which was chosen for its relatively high thermal conductivity at relatively low cost. Each plate was CNC machined to have a parallel flow serpentine water flow channel ( $4 \times 4 \mathrm{~mm} \times 7 \mathrm{~m}$ long) on one side and a perimeter groove on the other side to accommodate an O-ring vacuum seal. The chosen plate size was primarily determined by the constraints of the CNC machine. The plate surfaces forming the evaporator and condenser were not machined (standard smooth, dull, mill finish) but were cleaned using isopropyl alcohol to remove any grease.

- Two water-side cover plates (B3 \& B4) each consisting of a 300x500 mm piece of $6 \mathrm{~mm}$ thick aluminium plate. Holes were drilled to accommodate vacuum fittings, water supply connections, and clamping bolts. 
385 Figure 7 shows a schematic of the PLVTD test apparatus, consisting of the insulated 386 PLVTD (components A, B \& C), the measurement datalogger (D), the hot and cold 387 water supply system ( $E \&$ F) and the vacuum pump system (G). The datalogger 388 monitored flow rates $(M)$, temperatures $(T)$ and cavity pressure $(P)$. The horizontal 389 orientation of the PLVTD assembly $(A, B, C)$ was verified using a digital inclinometer 390 prior to tests.

391 Non-condensable gases were removed from the PLVTD cavity using the vacuum pump 392 before and after injection of the working fluid through the fill point. The working fluid 393 consisted of $0.28 \mathrm{~L}$ de-ionised water corresponding to approximately $2.5 \mathrm{~kg} / \mathrm{m}^{2}$ of 394 evaporator surface area. Cavity pressures were monitored throughout the tests and 395 maintained at $<25 \%$ above the expected saturation pressure by repeating evacuation 396 (prior to, but not during, each measurement) to remove the small amounts of non397 condensable gas which arose from air infiltration and outgassing. Slight loss of working 398 fluid due to repeated evacuations was observed $(0.26 \mathrm{~L}$ remaining after several days 399 of testing) but is not considered significant.

400 During each test, heat was supplied to one of the PLVTD plates from the water heating 401 circuit and removed from the other plate by the chilled water circuit. The two circuits 402 each featured insulated flexible pipework, one oval gear flow meter (M) and two 403 variable speed pumps which were arranged in series in order to overcome the high 404 pressure drop imposed by the water flow channels within each plate. An arrangement 405 of gate valves was used to regulate flow rates and to determine operating mode such 406 that, in forward mode, the evaporator was connected to the heating circuit and the 407 condenser was connected to the chilling circuit. Valve settings were inverted during 408 reverse mode operation to enable the plates to be connected the opposite way around. 409 Additional valves allowed the system to be filled or flushed with water from the mains 410 supply or drained down. Temperatures, flow rates and pressures were continuously 411 recorded throughout the experiments using the datalogger set to have a 1 minute 412 sampling time. Calibration checks indicated that the accuracy of temperature readings 413 provided by the thermocouples was $\pm 1.0^{\circ} \mathrm{C}$ for temperature readings indicated by any 414 one thermocouple and $\pm 0.3^{\circ} \mathrm{C}$ for temperature differences derived from readings 415 indicated by a pair of thermocouples. The uncertainty associated with the flow rate 416 readings was found to be $\pm 9 \%$ for volume flow rates of water in the range 100 to 1000 $417 \mathrm{~mL} / \mathrm{min}$ at temperatures in the range 5 to $75^{\circ} \mathrm{C}$. 


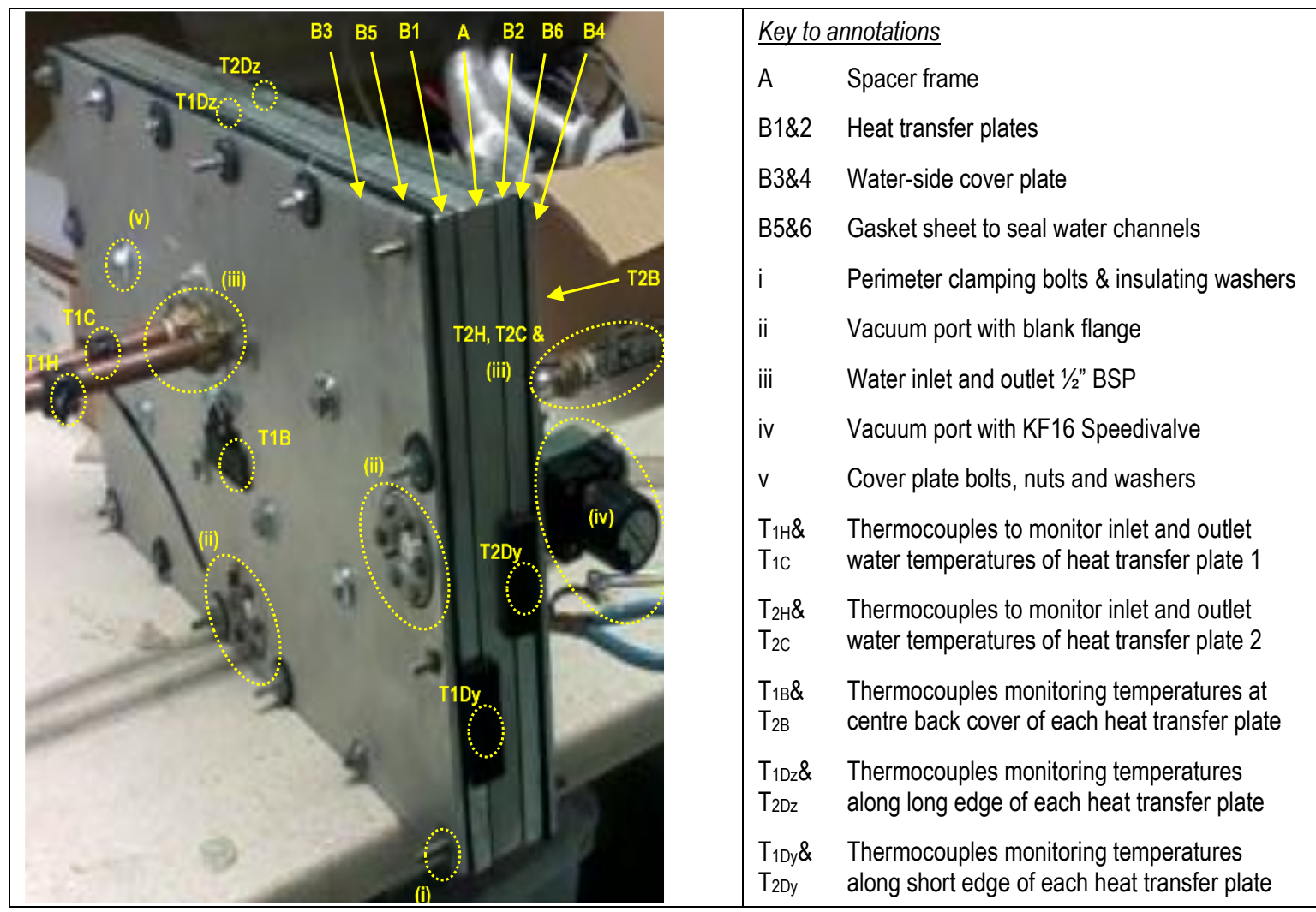

Figure 5 - Annotated photograph of the assembled prototype PLVTD

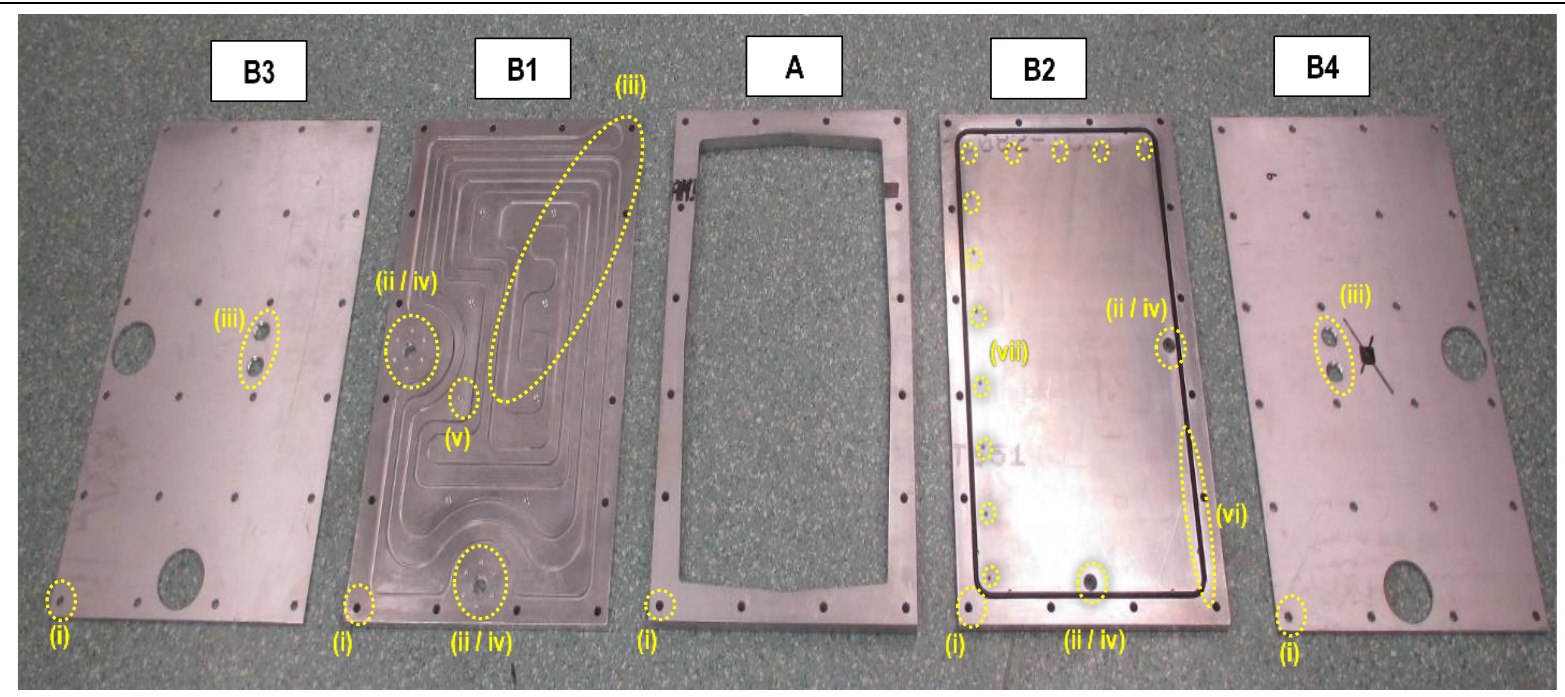

\section{$\underline{\text { Key to annotations }}$}

A Spacer frame

B1 \& B2 Heat transfer plate (12 mm aluminium). Both plates are identical but opposite sides are shown in the photograph.

B3 \& B4 Cover plate (6 mm aluminium).

i to $v \quad$ Holes for fixtures and fittings. Refer to Figure 5 for details.

vi Viton cylindrical section O-ring seal $5.3 \mathrm{~mm} \times 430 \mathrm{~mm}$.

vii Fixing holes for internal ancillary components (not used). 


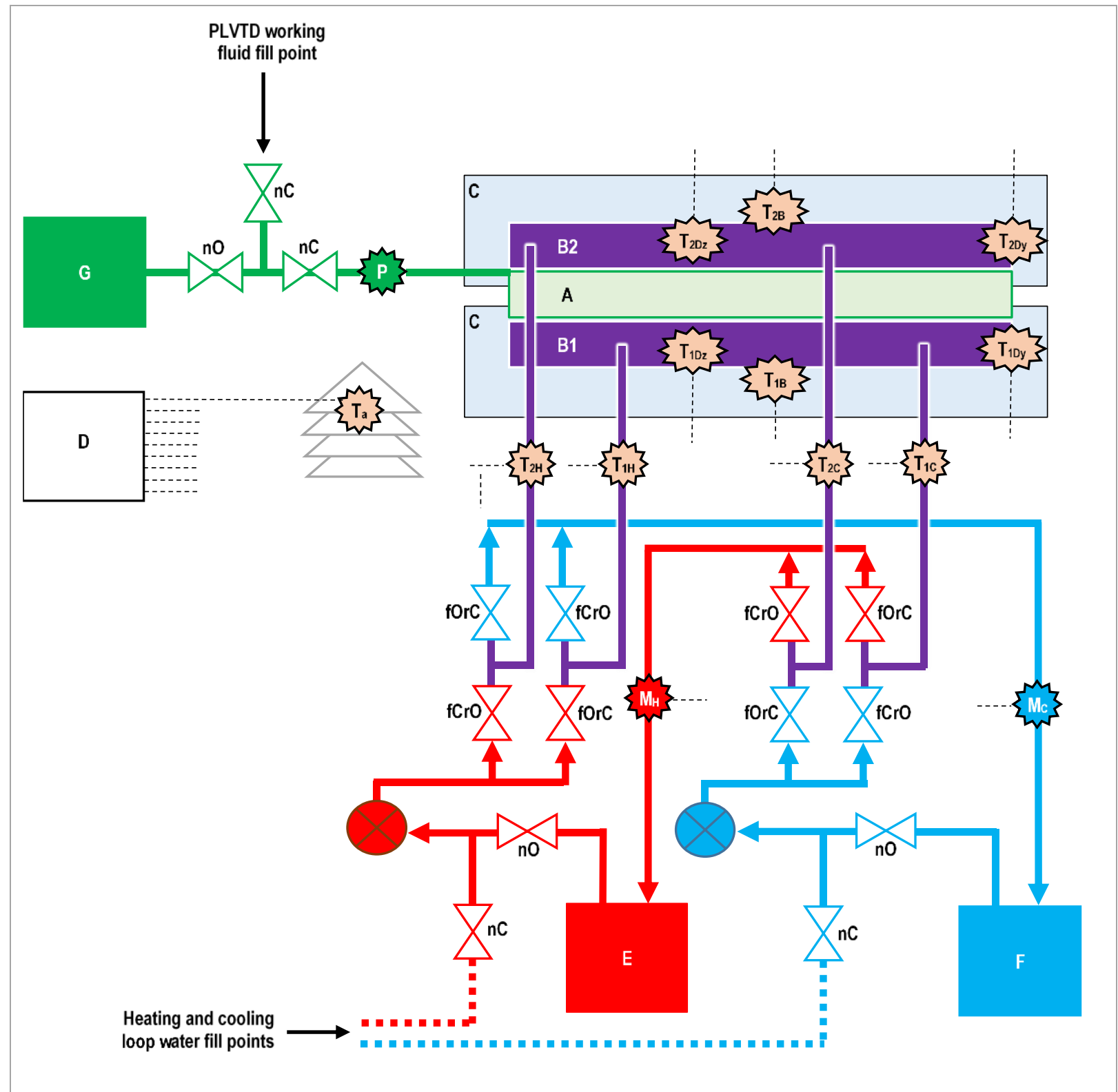

\section{Key to annotations:}
A Spacer frame
B Heat transfer plates and covers
C $50 \mathrm{~mm}$ polystyrene foam insulation
D DeltaT DL2e datalogger connected to computer
E Julabo ED19A heating circulator
F Julabo F33MA refrigerated-heating circulator
G Edwards XDS5 scroll vacuum pump

$\bigotimes \quad$ Wilo 4035479 SB30 water circulating pumps in series

$\$$ Gate valves, operation denoted by codes:

$\begin{aligned} \text { fOrC } & \text { Open in forward mode, Closed in reverse mode } \\ \text { fCrO } & \text { Closed in forward mode, Open in reverse mode } \\ \text { nO } & \text { Normally Open, except during filling } \\ \text { nC } & \text { Normally Closed, except during filling }\end{aligned}$

Measurement point, denoted by one of the following letters:
$\mathrm{M}$ Mass flow rate measurement using Nixon OG1 oval gear flow meter
P Vacuum pressure measurement using Edwards CG16K, Digitron 2025P \& Druck DPI-104 gauges Temperature measurement using T-type
$T$ thermocouples on the hot $\left(T_{H}\right)$ and cold $\left(T_{C}\right)$ pipe connections, at the back ( $\left.T_{B}\right)$ and edges ( $\left.T_{D y} \& T_{D z}\right)$ of the plates, and local ambient $\left(\mathrm{T}_{\mathrm{a}}\right)$ 
425 The heating and chilling circuit supply temperatures and flow rates determined the

426 amount of thermal power available for transfer through the PLVTD prototype and hence

427 also controlled the evaporator and condenser plate temperatures. The amount of heat

428 supplied $\left(\mathrm{q}_{\mathrm{HC}}\right)$ or removed $\left(\mathrm{q}_{\mathrm{CH}}\right)$ by each plate was determined from Equations 23 and

42924 respectively accounting for the inlet-to-outlet temperature differences $\left(\Delta T_{H C}=T_{H}-T_{C}\right.$

430 when supplying heat or $\Delta \mathrm{T}_{\mathrm{CH}}=\mathrm{T}_{\mathrm{C}}-\mathrm{T}_{\mathrm{H}}$ when removing it), the fluid mass flow rates fed

431 through the plates ( $\mathrm{M}_{\mathrm{HC}}$ and $\mathrm{M}_{\mathrm{CH}}$ respectively) and the specific heat capacity of that

432 fluid $\left(c_{p}\right)$ at its average temperature $T_{H C}=\left(T_{H}+T_{C}\right) / 2$. Heat supplied by one plate $\left(q_{H C}\right)$

433 should always be equal to the amount of heat removed by the other plate $\left(-\mathrm{q}_{\mathrm{CH}}\right)$ if

434 ambient losses are properly accounted for. The amount of heat lost $\left(q_{1}\right)$ from a hot

435 plate to the ambient environment (or gained from ambient by a cold plate) can be

436 determined according to Equation 25 based on the back-of-plate temperature $\left(T_{B}\right)$, the

437 edge-of-plate average temperature $\left(T_{D}=0.5 T_{D y}+0.5 T_{D z}\right)$ the ambient temperature $\left(T_{a}\right)$

438 and the heat loss thermal resistance $\left(R_{1}\right)$. In order to obtain reliable measurement

439 data, the inlet-to-outlet temperature differences ( $\Delta \mathrm{T}_{\mathrm{HC}}$ and $\Delta \mathrm{T}_{\mathrm{CH}}$ ) and plate-to-plate

440 temperature difference $\left(\Delta \mathrm{T}_{12}\right)$ need to be higher than the $\pm 0.3^{\circ} \mathrm{C}$ uncertainty

441 associated with such measurements. Temperature differences of $1.2^{\circ} \mathrm{C}$ would

442 theoretically have an uncertainty of $\pm 25 \%$. The magnitude of the plate-to-plate

443 temperature difference is dependent upon the heat flux flowing through the PLVTD

$444\left(\mathrm{q}_{\mathrm{HC}} / \mathrm{A}_{\mathrm{p}} \approx-\mathrm{q}_{\mathrm{CH}} / \mathrm{A}_{\mathrm{p}}\right)$ and the overall thermal conductance $\left(\mathrm{U}_{\mathrm{fr}}\right)$ of the PLVTD as described 445 by Equation 26.

446

$$
\Delta T_{12}=\frac{0.5\left(q_{H C}-q_{C H}\right)}{U_{f r} A_{p}}
$$

452 Figure 8 shows an example temperature, pressure and flow rate time history measured 453 during one set of forward mode tests. Numbered labels show five condenser plate 454 temperature setpoints corresponding to approximately $\mathrm{T}_{2}=15,25,35,45$ and $50^{\circ} \mathrm{C}$. 
455 Steady state temperatures were typically achieved about half an hour after each 456 setpoint change. Flow rates were maintained broadly constant at $457 \quad M_{\mathrm{HC}}=\mathrm{M}_{\mathrm{CH}}=0.65 \pm 0.1 \mathrm{~L} / \mathrm{min}$ throughout the tests. Measured pressures $\left(P_{\text {meas }}\right)$ increased 458 with increasing temperature and corresponded broadly to saturation pressure 459 estimates $\left(\mathrm{P}_{\mathrm{Lv}(\mathrm{HCCH})}\right)$ which were evaluated from the average flow and return 460 temperatures using REFPROP software (NIST, 2013). Figure 9 shows the corresponding 461 derived thermal powers ( $\mathrm{q}_{\mathrm{HC}}=-\mathrm{q}_{\mathrm{CH}}=400 \pm 30 \mathrm{~W}$ throughout the featured tests) and 462 thermal conductances which rose from $U_{f}=300 \mathrm{~W} \cdot \mathrm{m}^{-2} \mathrm{~K}^{-1}$ at the lowest operating 463 temperature up to $U_{\mathrm{f}}=430 \mathrm{~W} \cdot \mathrm{m}^{-2} \mathrm{~K}^{-1}$ at the highest operating temperature. Figures 10 464 and 11 present results comparing measured and modelled forward mode performances 465 at varying condenser temperature and plate-to-plate temperature difference set466 points, including several repeat tests to check repeatability. Measured thermal 467 conductances varied from $\mathrm{U}_{\mathrm{f}}=150$ to $500 \mathrm{~W} \cdot \mathrm{m}^{-2} \mathrm{~K}^{-1}$. These have been compared to 468 corresponding values predicted by the theoretical model which was implemented as a 469 Microsoft Excel spreadsheet with supporting Visual Basic macros and lookup tables to 470 evaluate working fluid thermodynamic properties based on REFPROP software outputs.

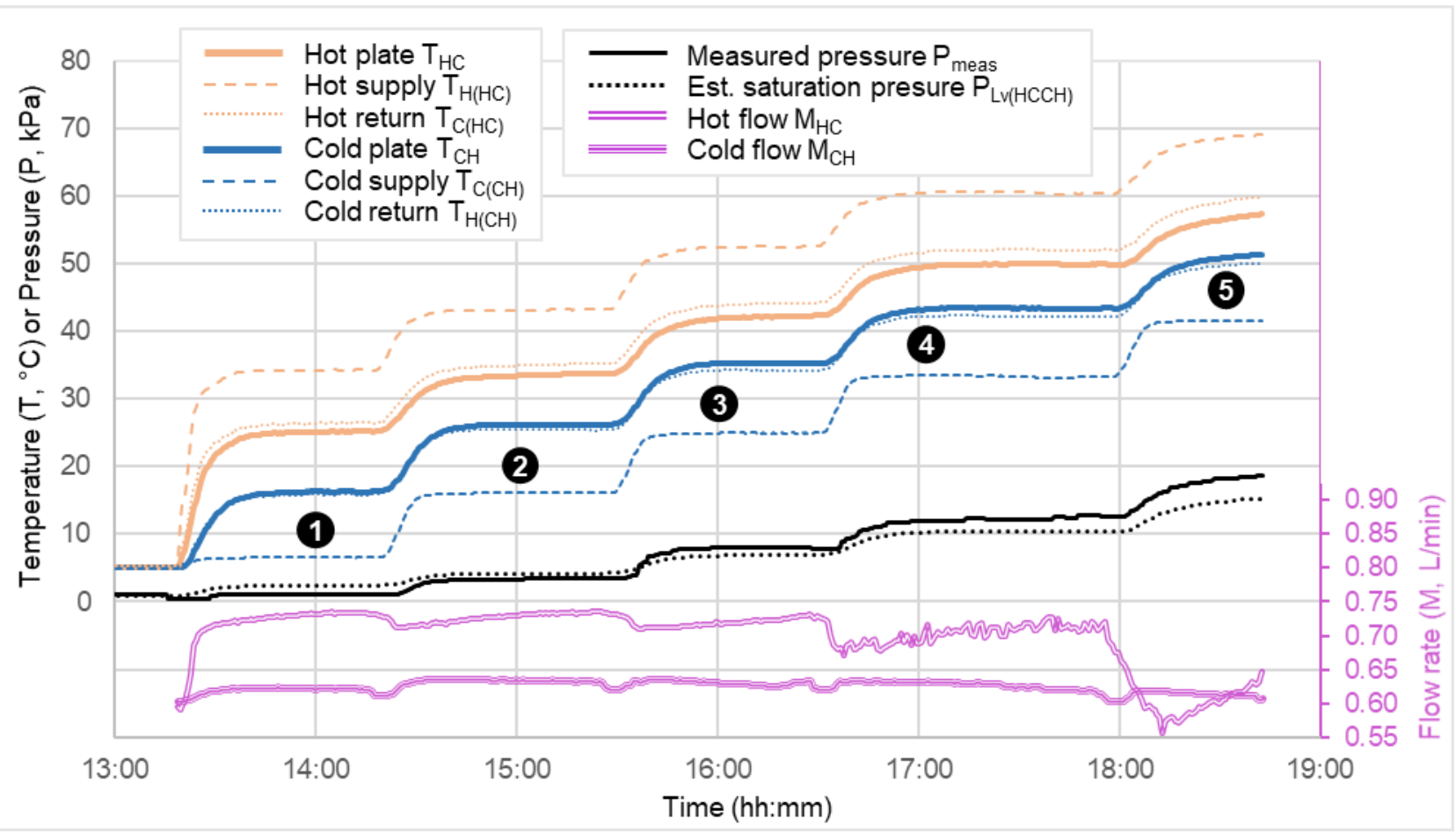

472 Figure 8 - Time history of measured temperatures, pressures \& flows during forward mode tests with $11 \mathrm{~mm}$ nylon spacer 473 
475

476

477

478

479

480

481

482

483

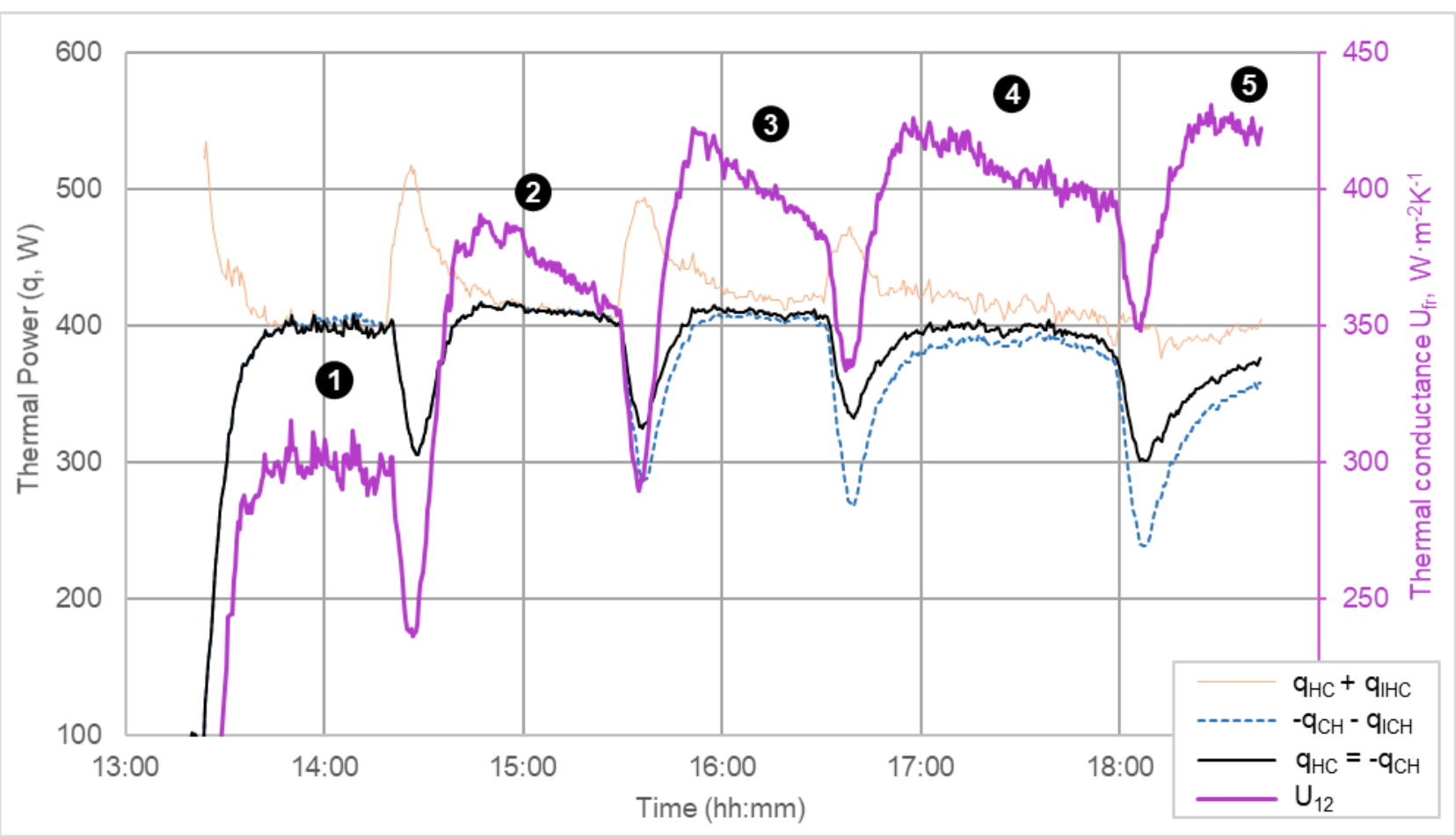

Figure 9 - Time history of derived thermal powers and conductance during forward mode tests with $11 \mathrm{~mm}$ nylon spacer

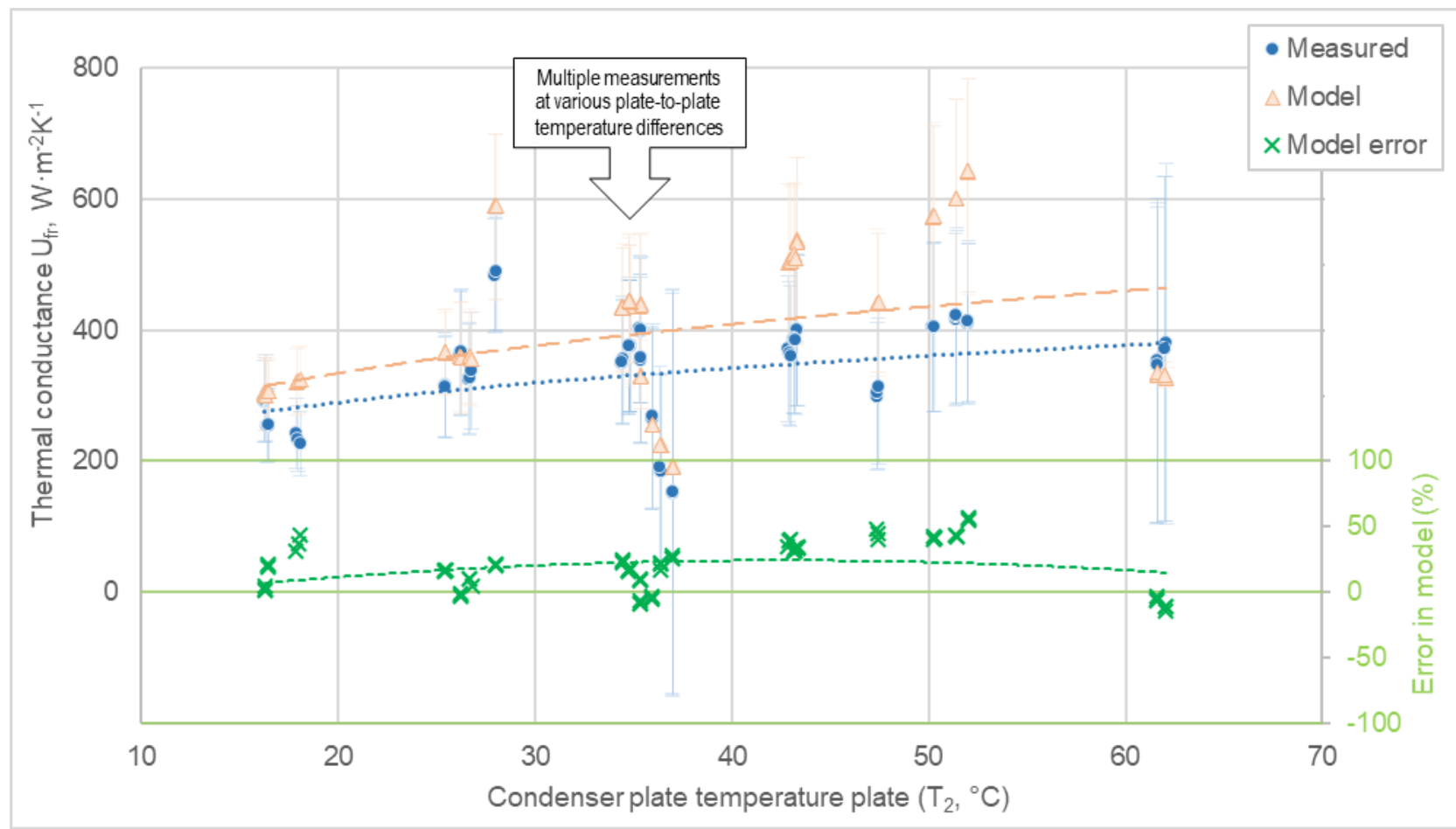

Figure 10 - Forward mode performance of PLVTD with $11 \mathrm{~mm}$ nylon spacer (varying condenser plate temperature) 


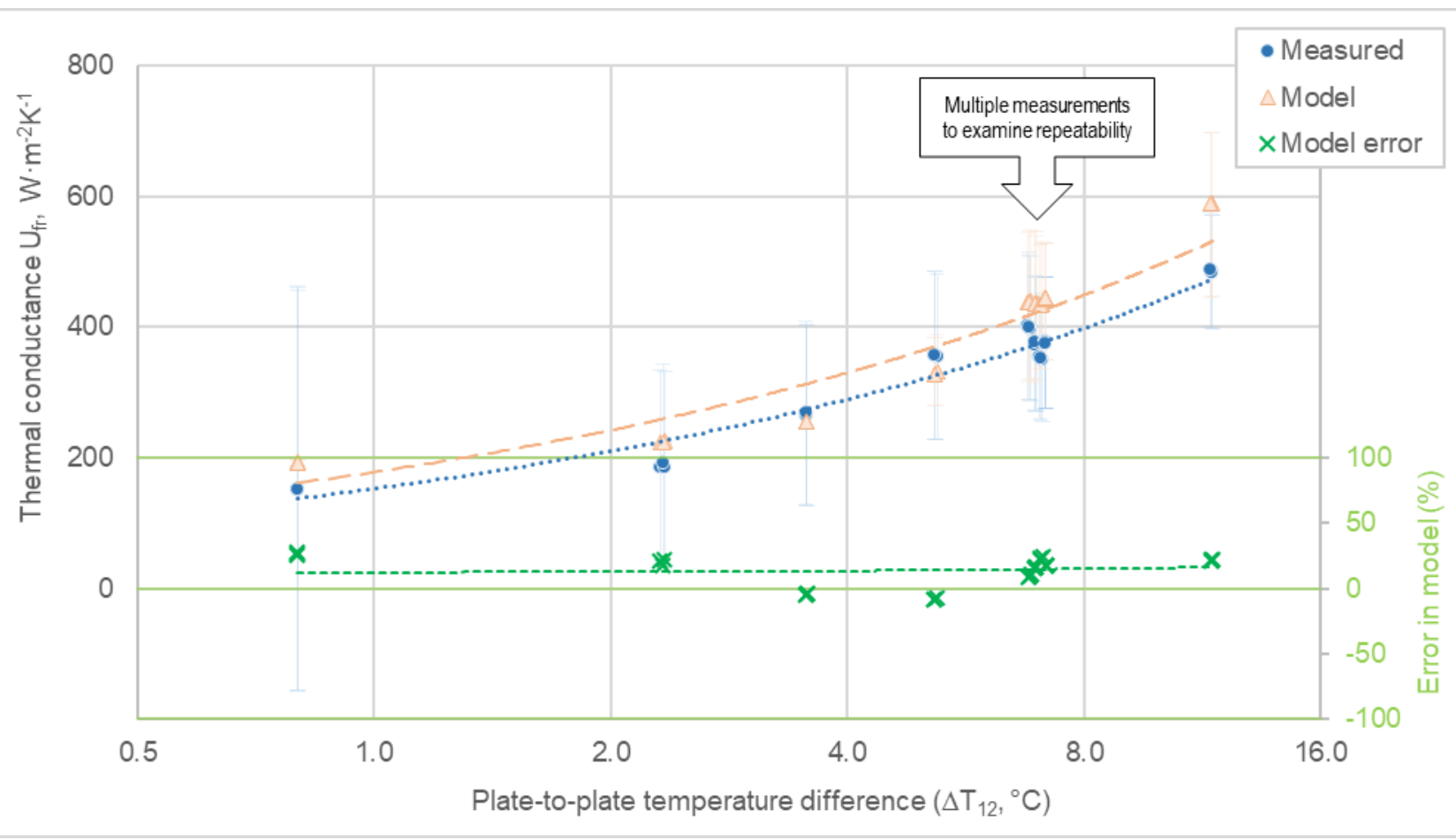

Figure 11 - Forward mode performance of PLVTD with $11 \mathrm{~mm}$ nylon spacer (varying plate-to-plate temperature difference)

The measurement and modelling results show clearly that forward mode thermal conductance increases with increasing condenser temperature $\left(T_{2}\right)$ and with increasing plate-to-plate temperature difference $\left(\Delta \mathrm{T}_{12}\right)$. Detailed examination of the model suggests that this is primarily due to decreases in evaporation thermal resistance $\left(R_{e}\right)$ and vapour mass flow resistance $\left(R_{\mathrm{ec}}\right)$ caused by reductions in working fluid viscosity as temperature increases and by increased driving forces as plate-to-plate temperature differences (and hence saturation pressure differences) increase.

Error bars on the graphs indicate estimated combined measurement uncertainties (95\% confidence limits) which are primarily associated with temperature and temperature difference measurement uncertainties. Results for cases where plate-toplate temperature differences exceed $\Delta T_{12}>4^{\circ} \mathrm{C}$ have measurement uncertainties of less than $\pm 40 \%$ but uncertainty increases at lower plate-to-plate temperature differences. Uncertainties propagate into the modelled results because measured plate temperatures are used as a calculation input parameter. Notwithstanding the declared measurement uncertainties (which have been estimated using a very conservative approach) it is clear that the model predicts the measured forward mode heat transfer behaviour reasonably well. An inherent bias is apparent in the data causing the model to consistently overpredict the heat transfer coefficients by $+20 \%$ relative to the measured data. There are a number of possible reasons for this bias but the most likely explanation is the presence of non-condensable gasses (air) in the PLVTD which 
507 increases thermal resistances associated with vapour mass transfer ( $\left.R_{e c}\right)$ and 508 condensation $\left(R_{c}\right)$ as described by Stein et al. (1985) and Peterson (1996). This 509 explanation is consistent with the fact that measured pressures ( $\left.P_{\text {meas }}\right)$ were in some 510 cases up to $25 \%$ higher than the estimated saturation pressures $\left(\mathrm{P}_{\mathrm{Lv}(\mathrm{HCCH})}\right)$ as apparent 511 in results towards the right of Figure 8.

512 Figures 12 and 13 present results comparing measured and modelled reverse mode 513 performances at varying condenser plate temperatures and varying plate-to-plate 514 temperature difference set-points. The measured thermal conductance was 515 consistently around $\mathrm{U}_{\mathrm{r}}=10 \mathrm{~W} \cdot \mathrm{m}^{-2} \mathrm{~K}^{-1}$ as predicted by the model and largely unaffected 516 by varying plate temperatures or temperature differences. Detailed examination of the 517 model suggests that conduction through PLVTD side walls (the $11 \mathrm{~mm}$ nylon spacer 518 frame, vacuum seals, and perimeter bolts) is the dominant heat transfer path 519 amounting to $\mathrm{U}_{\mathrm{w}}=6.7 \mathrm{~W} \cdot \mathrm{m}^{-2} \mathrm{~K}^{-1}$. Gaseous conduction through water vapour in the cavity 520 amounts to $\mathrm{U}_{\mathrm{v}}=1.8 \mathrm{~W} \cdot \mathrm{m}^{-2} \mathrm{~K}^{-1}$ and radiant heat transfer amounts to $\mathrm{U}_{\mathrm{R}}=1.1 \mathrm{~W} \cdot \mathrm{m}^{-2} \mathrm{~K}^{-1}$.

521

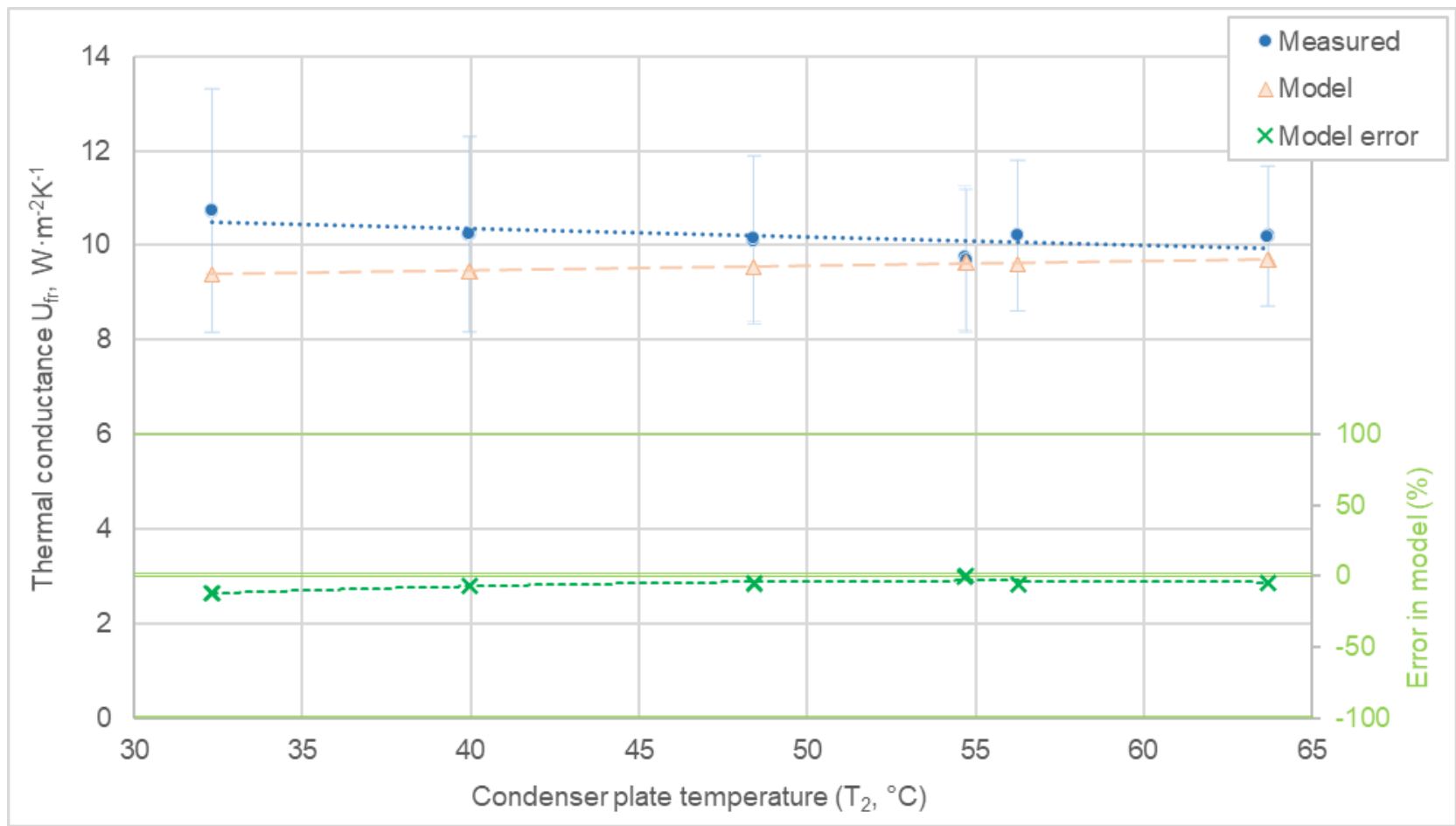

523

Figure 12 - Reverse mode performance of PLVTD with $11 \mathrm{~mm}$ nylon spacer (varying condenser plate temperature) 


\section{9}

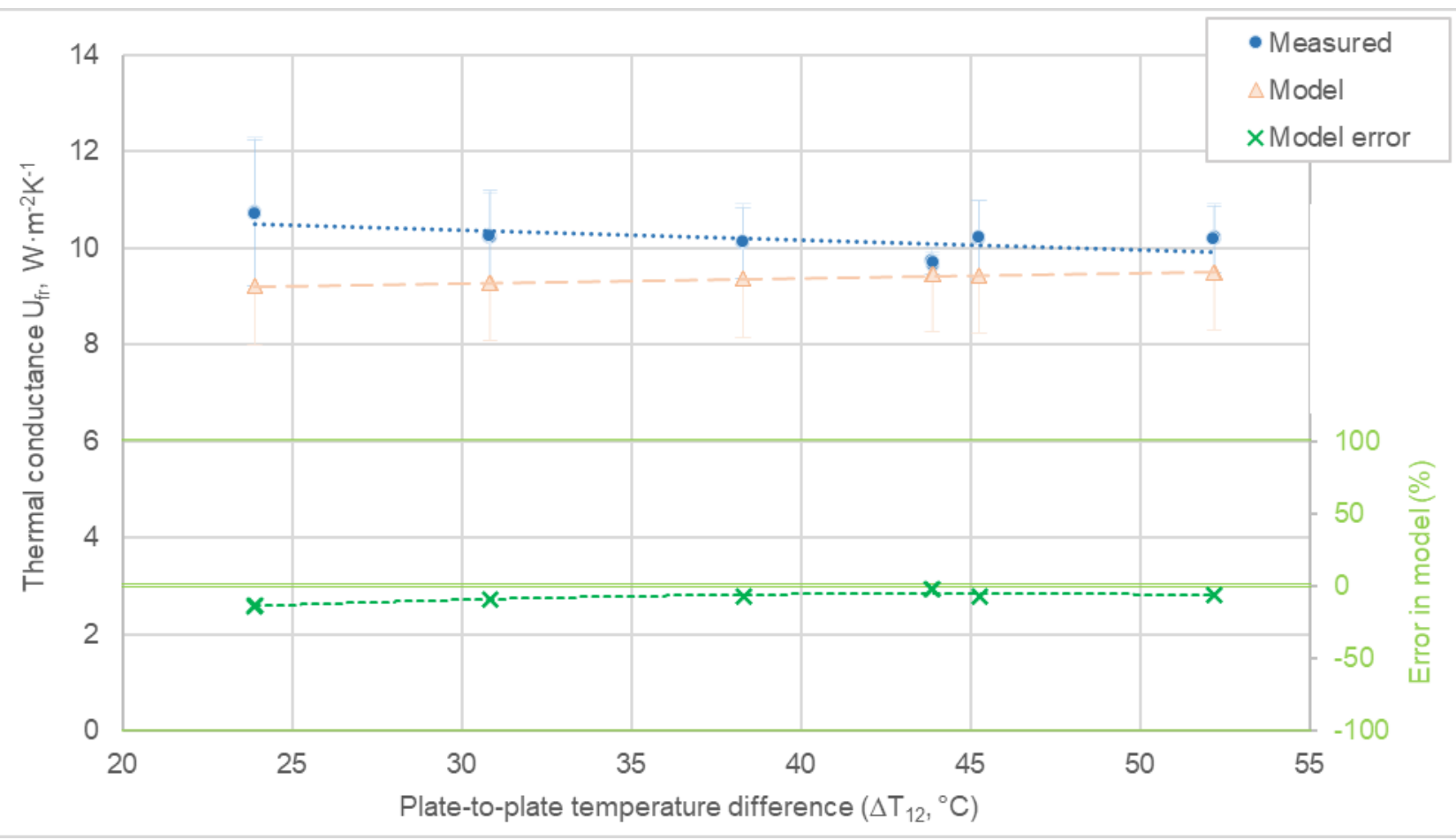

Figure 13 - Reverse mode performance of PLVTD with $11 \mathrm{~mm}$ nylon spacer (varying plate-to-plate temperature difference)

\section{Discussion}

The measurement results provide a reasonable validation for the theoretical results despite significant uncertainty associated with measurements of inherently small plateto-plate and inlet-outlet water circuit temperature differences. The forward mode heat transfer performances in the range $150<\mathrm{U}_{\mathrm{f}}<500 \mathrm{~W} \cdot \mathrm{m}^{-2} \mathrm{~K}^{-1}$ combined with the reverse mode insulation of $\mathrm{U}_{\mathrm{r}}=10 \mathrm{~W} \cdot \mathrm{m}^{-2} \mathrm{~K}^{-1}$ corresponds to diodicity of $\varsigma \approx 88 \%$ at low condenser temperatures and low heat fluxes $\left(T_{2} \approx 15^{\circ} \mathrm{C}\right.$ and $\left.\mathrm{q} / \mathrm{A} \approx 120 \mathrm{~W} \cdot \mathrm{m}^{-2}\right)$ and $\varsigma \approx 96 \%$ at high condenser temperatures and high heat fluxes $\left(T_{2} \approx 60^{\circ} \mathrm{C}\right.$ and $\left.\mathrm{q} / \mathrm{A} \approx 2800 \mathrm{~W} \cdot \mathrm{m}^{-2}\right)$. Forward mode performance increases with increasing heat flux and (to a lesser extent) with increasing operating temperature. Reverse mode performance is largely independent of heat flux and temperature within the ranges investigated.

Comparing with the work of Boreyko \& Chen (2011 \& 2013) and Traipattanakul et al. (2019) suggests that the PLVTD examined in this study achieves similar or lower reverse mode (better thermal insulation) performances but somewhat lower forward mode (worse heat transfer) performances. The theoretical model indicates that the reverse mode performance is largely governed by cavity depth and the influence of thermal bridging elements (sidewalls and supporting structure) hence the findings are unsurprising given that cavity depths are of broadly similar magnitudes. The lower forward mode performance achieved in the present study is partly attributable to heat 
548 flux (authors cited above examined behavior at higher heat fluxes) but more

549 importantly due to the simple design of the evaporator and condenser (authors cited

550 above used hydrophobic condenser coatings and hydrophilic evaporator wick coatings

551 to boost performance). Compared to the simple thermosyphonic thermal diode

552 investigated by Wong et al. (2019) the evacuated PLVTD examined in this study

553 achieves better performance in both forward and reverse modes, despite having a

554 smaller cavity depth. Evacuation reduces natural convection in reverse mode due to

555 removal of non-condensable gases and increases latent heat transfer in forward mode

556 because the cavity pressure is similar to the working fluid saturation pressure.

557 A key consideration for solar collector and climate control building envelope 558 applications is the thermal insulation performance (reverse mode) which typically 559 needs to be in the range offered by conventional insulation materials. For reference, 560 high quality double glazing typically achieves $\mathrm{U} \approx 1.2 \mathrm{~W} \cdot \mathrm{m}^{-2} \mathrm{~K}^{-1}$ and fibre or foam-based 561 insulation products (assuming $50 \mathrm{~mm}$ thick) achieve $\mathrm{U} \approx 0.7 \mathrm{~W} \cdot \mathrm{m}^{-2} \mathrm{~K}^{-1}$. These values are 562 considerably lower (better) than those achieved by the PLVTD examined in this study 563 or by most other authors. Heat transfer performance of around $1000 \mathrm{~W} \cdot \mathrm{m}^{-2} \mathrm{~K}^{-1}$ is a 564 reasonable target for PLVTD forward mode performance when integrated in solar 565 thermal collectors (Dupeyrat et al., 2011). Analysis suggests that the overall collection 566 efficiency of a solar water heater would not be significantly affected by a 5-fold increase 567 or decrease to this target (Pugsley, 2017).

568 Using the theoretical model it is possible to examine a variety of PLVTD design options 569 in order optimise performance for solar collector and climate control building envelope 570 applications. Figure 14 shows how reverse mode performance $\left(U_{v}\right)$ via natural 571 convection of water vapour is dependent upon the cavity depth $(L \approx x)$ for nominal 572 assumed operating conditions $\left(\mathrm{T}_{1}=10^{\circ} \mathrm{C}\right.$ and $\left.\mathrm{T}_{2}=60^{\circ} \mathrm{C}\right)$. Calculations consider plate-to573 plate cavity depths in the range $10 \leq x \leq 200 \mathrm{~mm}$. It is very clear that increasing the 574 cavity depth improves the insulation performance. Figures 15 and 16 show the 575 calculated variation of reverse and forward mode performances with temperature for 576 a PLVTD of dimensions $x=70 \mathrm{~mm}, y=0.7 \mathrm{~m}$ and $z=1.4 \mathrm{~m}$ constructed of $x_{p}=z_{w}=1 \mathrm{~mm}$ 577 thick stainless plates and sidewalls with internal supporting structure formed of 578 stainless steel tubular struts $\left(d_{s}=8 \mathrm{~mm}\right.$ diameter and $d_{s w}=1 \mathrm{~mm}$ wall thickness) spaced 579 at $d_{s s}=2{ }_{d s x y}=2_{d s x z}=0.07 m$ centres. The results demonstrate that such a design should 580 be capable of achieving insulation performances which are close to those desired and 581 diodicity $\varsigma>97 \%$. It is interesting to note that the performances shown on Figures 15 582 and 16 are very similar to those shown on Figures 10 and 11, highlighting that forward 583 mode performance of a horizontal PLVTD is largely independent of dimensions. 
584 Figure 17 shows that forward mode heat transfer is linearly dependent upon the plate585 to-plate temperature difference below $\Delta T_{12}=3^{\circ} \mathrm{C}$ but follows an exponential 586 relationship at higher plate temperature differences. The knee point corresponds to 587 heat fluxes $>1500 \mathrm{~W} \cdot \mathrm{m}^{-2}$ which may be of relevance to concentrating solar applications. 588 Pugsley (2016) constructed and tested a hybrid photovoltaic thermal integrated 589 collector-storage solar water heater incorporating a PLVTD which had dimensions 590 similar to those examined in Figures 15 to 17. The PLVTD achieved reverse mode 591 performance of $U_{r}=1.7 \mathrm{~W} \cdot \mathrm{m}^{-2} \mathrm{~K}^{-1}$ which enabled a satisfactory overall loss coefficient $592\left(U_{\text {sys }}=0.85 \mathrm{~W} \cdot \mathrm{m}^{-2} \mathrm{~K}^{-1}\right)$ to be achieved when the solar absorber was fitted with a 593 rudimentary transparent plastic cover. The forward mode performance $594\left(\mathrm{U}_{\mathrm{f}}=45 \mathrm{~W} \cdot \mathrm{m}^{-2} \mathrm{~K}^{-1}\right.$, similar to that achieved by Wong et al., 2019) was lower than 595 expected owing to problems with dry patches on the evaporator surface. Overall 596 diodicity $(s=93 \%)$ was marginally lower than expected.

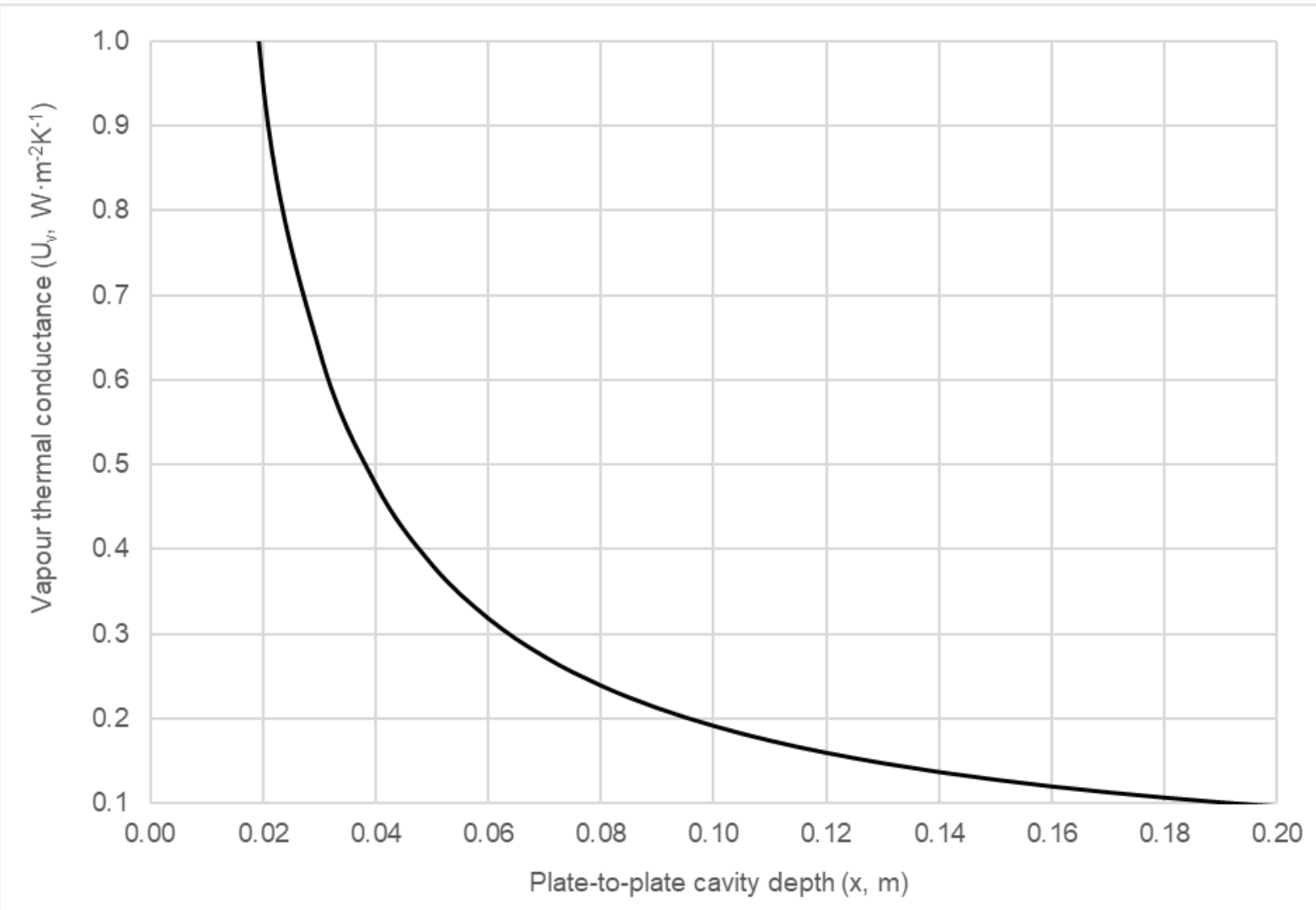




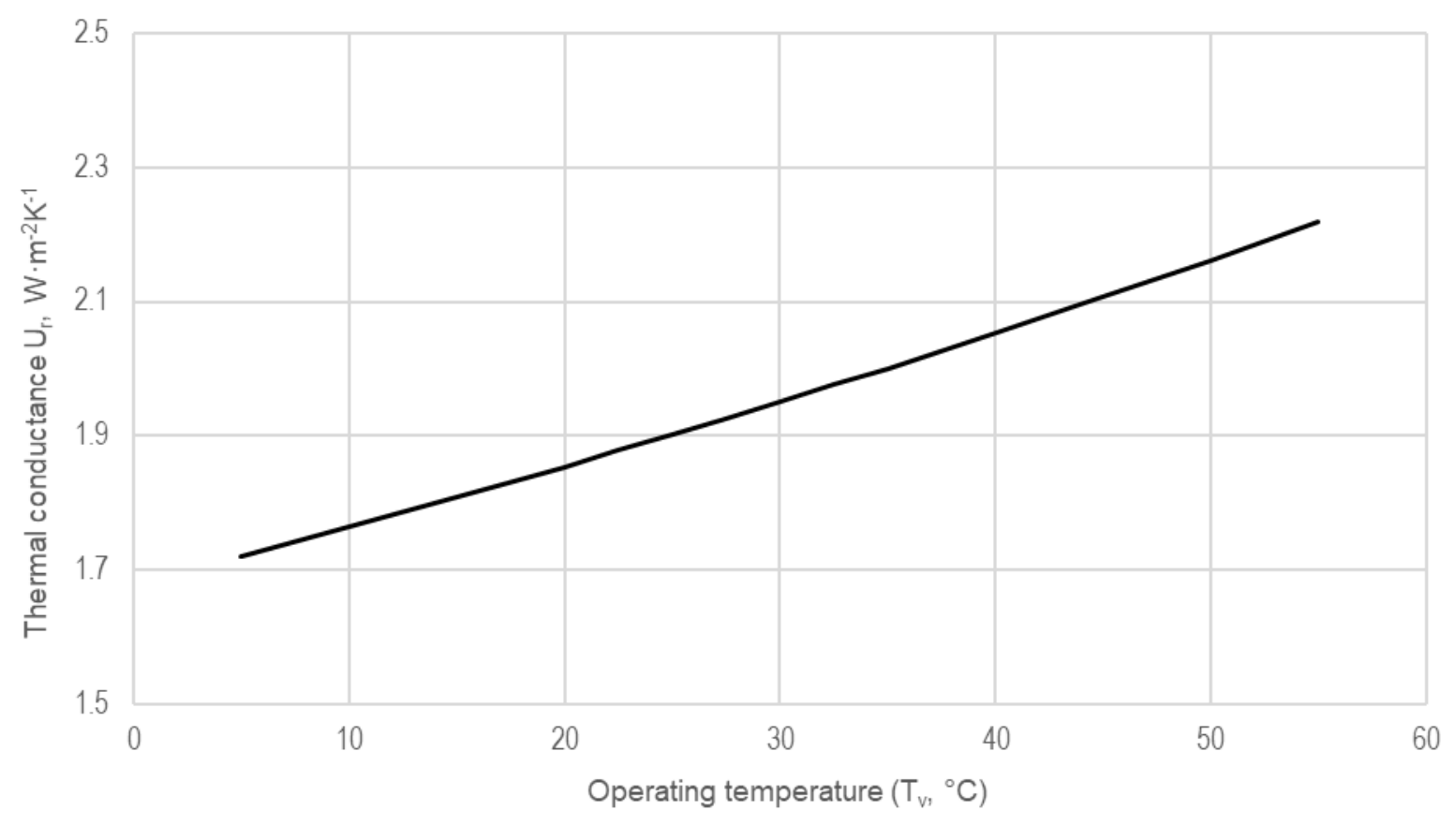

603 Figure 15 - Reverse mode temperature dependence $\left(\Delta T_{12}=50^{\circ} \mathrm{C}\right)$ for a horizontal $x=0.07, y=0.7, z=1.4 \mathrm{~m}$ stainless steel PLVTD 604

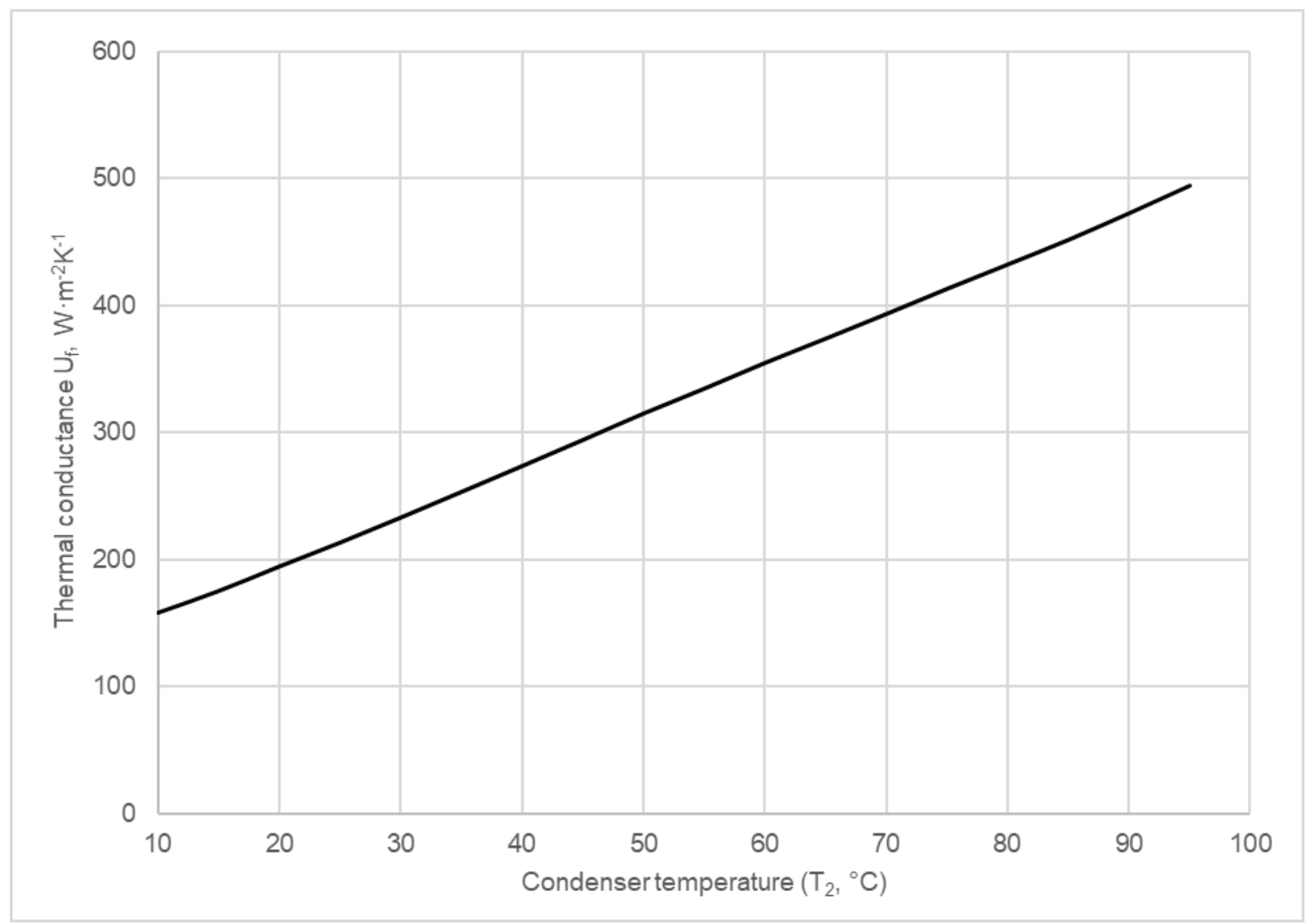

606 Figure 16 - Forward mode temperature dependence $\left(\Delta T_{12}=1.5^{\circ} \mathrm{C}\right)$ for a horizontal $x=0.07, y=0.7, z=1.4 \mathrm{~m}$ stainless steel PLVTD 607 608 


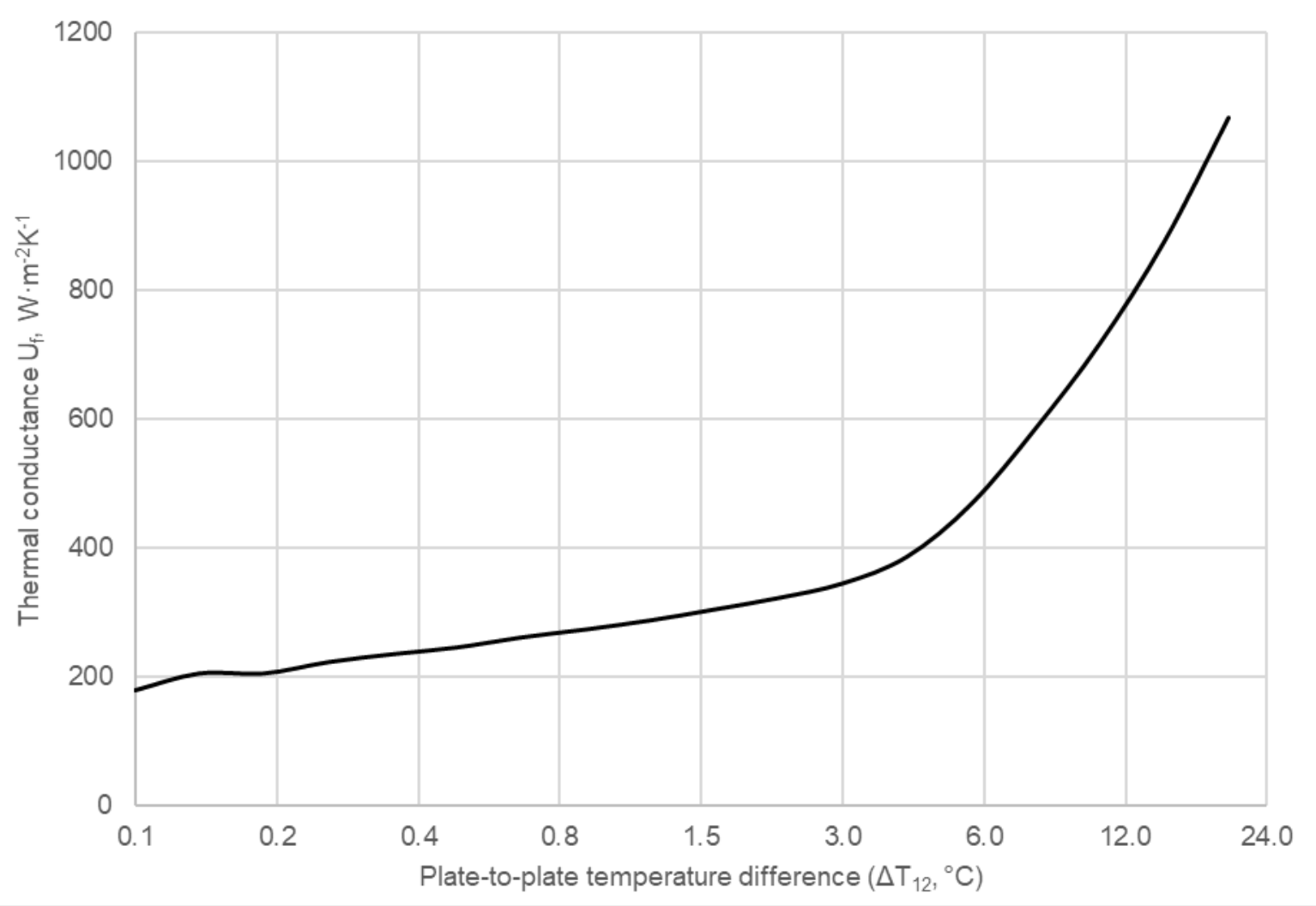

Figure 17 - Forward mode heat-flux dependence $\left(T_{2}=45^{\circ} \mathrm{C}\right)$ for a horizontal $x=0.07, y=0.7, z=1.4 \mathrm{~m}$ stainless steel PLVTD

\section{Conclusions}

613 The heat transfer behaviour of a horizontal planar liquid-vapour thermal diode (PLVTD)

614 has been examined with the aim of supporting engineering for applications in solar 615 thermal collectors and climate control building envelopes. An experimental PLVTD was 616 fabricated and its forward mode heat transfer and reverse mode thermal insulation 617 characteristics were quantified. The experimental device $\left(A_{p}=0.15 \mathrm{~m}^{2}\right.$ and $\left.\mathrm{x}=11 \mathrm{~mm}\right)$ 618 examined in this study had a much larger area and wider cavity than PLVTDs reported 619 elsewhere in the literature $\left(A_{p}<0.01 \mathrm{~m}^{2}\right.$ and $\left.1<x<7 \mathrm{~mm}\right)$. The experimental work 620 involved a horizontally oriented PLVTD formed of two parallel isothermal plates with 621 integral serpentine heat exchangers and external insulation. Temperature difference 622 between the plates was controlled by connecting each serpentine heat exchanger to a 623 separate heating-cooling fluid circuit. Plate, fluid, and ambient temperatures were 624 measured to determine heat transfer coefficients under various temperature difference 625 and heat flux operating scenarios. Forward mode heat transfer performances were 626 found to be in the range $150<U_{\mathrm{f}}<500 \mathrm{~W} \cdot \mathrm{m}^{-2} \mathrm{~K}^{-1}$ and reverse mode insulation was $\mathrm{U}_{\mathrm{r}}=10$ $627 \mathrm{~W} \cdot \mathrm{m}^{-2} \mathrm{~K}^{-1}$. Forward mode performance was found to increase with increasing heat flux 628 (in the range $120<q / A_{p}<2800 \mathrm{~W} \cdot \mathrm{m}^{-2}$ ) and to a lesser extent with increasing operating 629 temperature (condenser plate temperatures in the range $15<\mathrm{T}_{2}<60^{\circ} \mathrm{C}$ ). Reverse mode 
630 performance appears to be largely independent of heat flux and temperature within

631 the ranges investigated. The measured results correspond to diodicity in the range $63288<\varsigma<96 \%$.

633 A one-dimensional lumped parameter heat transfer model has been proposed and 634 successfully validated using the experimental results. Examination of the model shows 635 that behaviour in forward mode is largely governed by the evaporation thermal 636 resistance $\left(R_{e}\right)$ and vapour mass flow resistance $\left(R_{e c}\right)$ which are sensitive to working 637 fluid viscosity and plate-to-plate temperature differences. The experimental work was 638 undertaken with non-condensable gases removed as far as possible, although a degree 639 of outgassing appears to have taken place during measurements. The vapour mass 640 flow resistance $\left(R_{e c}\right)$ and the condensation thermal resistance $\left(R_{c}\right)$ are sensitive to non641 condensable gases resulting the model generally overestimating the measured forward 642 mode performance by about $20 \%$. Reverse mode performance is largely governed by 643 cavity depth which determines the thermal resistance of the sidewalls $\left(R_{w}\right)$, the 644 supporting structural elements $\left(R_{s}\right)$, and the gaseous conduction and convection across 645 the cavity $\left(R_{v}\right)$. The radiative resistance between the two plates $\left(R_{r}\right)$ had only a small 646 effect on the overall behavior of the device tested.

647 Whilst maximisation of forward mode heat transfer has been a priority for researchers 648 examining PLVTDs for electronics cooling applications, minimisation of reverse mode 649 heat transfer (ie improving the insulation performance) is the primary focus for PLVTDs 650 in solar collector and climate control building envelope applications. The theoretical 651 model has been used to calculate the forward and reverse mode performance of a 652 large area $\left(A_{p}=1 \mathrm{~m}^{2}\right)$ wide cavity $(x=70 \mathrm{~mm})$ PLVTD constructed of $1 \mathrm{~mm}$ stainless plates 653 and sidewalls with internal supporting structure formed of stainless-steel tubular struts 654 spaces at $70 \mathrm{~mm}$ centres. The results demonstrate that such a design should be capable 655 of achieving forward mode heat transfer of $150<\mathrm{U}_{\mathrm{f}}<500 \mathrm{~W} \cdot \mathrm{m}^{-2} \mathrm{~K}^{-1}$, reverse mode heat 656 transfer of $U_{r}=2 \mathrm{~W} \cdot \mathrm{m}^{-2} \mathrm{~K}^{-1}$ and diodicity of $\varsigma>97 \%$, which would be suitable for solar 657 collector and climate control building envelope applications.

658 The work presented in this paper is limited to simple horizontally oriented PLVTDs 659 where evaporator wetting and condensate return is driven by gravity. The authors 660 have subsequently examined the behaviour of modified PLVTDs in vertical and tilted 661 orientations. Experimental results for vertically oriented PLVTDs together with a 662 modified version of the lumped parameter model (to account for orientation) will be 663 presented in a future publication. 


\section{Acknowledgements}

665 This research was enabled in its early stages by studentship funding support from the

666 Northern Ireland Department for the Economy. The work was subsequently progressed 667 with funding support from SolaForm Ltd and was completed as part of the "SolaFin2Go" 668 project funded by the UKRI Engineering and Physical Sciences Research Council 669 (EP/R035954/1) and Innovate UK Energy Catalyst Round 5 (IUK/133219). The authors 670 would also like to thank networking support funded by the European Union FP7 COST 671 Action TU1205 "Building Integration of Solar Thermal Systems".

\section{$6729 \quad$ Nomenclature}

\section{Latin symbols}

674 A Surface area $\left[\mathrm{m}^{2}\right]$

$675 \quad c_{p} \quad$ Specific heat capacity at constant pressure $\left[\mathrm{J} \cdot \mathrm{kg}^{-1} \mathrm{~K}^{-1}\right]$

$676 \mathrm{~d} \quad$ Distance $[\mathrm{m}]$

$677 \mathrm{~g}$ Acceleration due to gravity $\left(\mathrm{g}=9.81 \mathrm{~m} \cdot \mathrm{s}^{-2}\right.$ on earth at sea level)

$678 \mathrm{~h}_{\mathrm{Lv}} \quad$ Latent heat of liquid-vapour phase change $\left[\mathrm{J} \cdot \mathrm{kg}^{-1}\right]$

$679 \mathrm{k} \quad$ Thermal conductivity $\left[\mathrm{W} \cdot \mathrm{m}^{-1} \mathrm{~K}^{-1}\right]$

$680 \mathrm{~L} \quad$ Characteristic dimension of Nusselt number [m]

$681 \mathrm{M} \quad$ Mass flow rate $\left[\mathrm{kg} \cdot \mathrm{s}^{-1}\right]$

$682 \mathrm{~N} \quad$ Number of struts in structural support array

$683 \mathrm{Nu} \quad$ Nusselt number

$684 \mathrm{P} \quad$ Pressure $[\mathrm{Pa}]$

$685 \mathrm{Pr} \quad$ Prandtl number

686 q Thermal power [W]

$687 \mathrm{Ra} \quad$ Rayleigh number

$688 \mathrm{~T} \quad$ Temperature $\left[{ }^{\circ} \mathrm{C}\right]$ except for Equation 10 which uses absolute $[\mathrm{K}]$

$689 \mathrm{U} \quad$ Thermal conductance or heat transfer coefficient $\left[\mathrm{W} \cdot \mathrm{m}^{-2} \mathrm{~K}^{-1}\right]$

$690 \quad \mathrm{~V} \quad$ Kinematic viscosity $\left[\mathrm{m}^{2} \cdot \mathrm{s}^{-1}\right]$

$691 \times \quad$ Distance along an axis which is parallel to the PLVTD depth [m]

692 y Distance along horizontal axis perpendicular to PLVTD depth [m]

$693 \mathrm{z} \quad$ Distance along an axis which is perpendicular to $\mathrm{x}$ and $\mathrm{y}$ axes [m]

694 Greek and other symbols

$695 \mathcal{M} \quad$ Molecular weight $\left[\mathrm{g} \cdot \mathrm{mol}^{-1}\right]$

$696 \mathcal{R} \quad$ Universal gas constant $\left(8.314 \mathrm{~J} \cdot \mathrm{mol}^{-1} \mathrm{~K}^{-1}\right)$

$697 \vartheta \quad$ Thermal diffusivity $\left[\mathrm{m}^{2} \cdot \mathrm{s}^{-1}\right]$ 


$\begin{array}{lll}698 & \Delta \mathrm{P} & \text { Pressure difference }[\mathrm{Pa}] \\ 699 & \Delta \mathrm{T} & \text { Temperature difference }\left[{ }^{\circ} \mathrm{C}\right] \\ 700 & \varsigma & \text { Diodicity }[\%] \\ 701 & \sigma & \text { Surface tension }\left[\mathrm{N} \cdot \mathrm{m}^{-1}\right] \\ 702 & \beta & \text { Coefficient of volumetric expansion }\left[\mathrm{K}^{-1}\right] \\ 703 & \rho & \text { Density }\left[\mathrm{kg} \cdot \mathrm{m}^{-3}\right] \\ 704 & \chi & \text { Stefan Boltzmann constant }\left(5.67 \times 10^{-8} \mathrm{~W} \cdot \mathrm{m}^{-2} \mathrm{~K}^{-4}\right)\end{array}$

\section{Subscripts}

$7061 \quad$ Plate 1 which is the evaporator in forward mode

7072 Plate 2 which is the condenser on forward mode

70812 Between (or average of) the two plates

709 a Ambient environment

710 B Back of plate

711 C Condenser, condensate or condensation

712 C Cold water feed or cooled return

$713 \quad \mathrm{CH} \quad$ Cooling plate or cooling water circuit

714 D Edge of plate

715 e

Evaporator, evaporation or evaporator liquid film

716 ec

Between (or average of) the evaporator and condenser surfaces

$717 \mathrm{f}$

Forward mode

$718 \mathrm{H}$

Hot water feed or heated return

$719 \mathrm{HC}$

Heating plate of heated water circuit

$720 \quad$ L

Working fluid liquid state property

$721 \quad 1$

Losses to ambient environment

722 L1

Liquid on the evaporator

723 L2

Liquid on the condenser

724 LV

Latent property of working fluid at the liquid-vapour saturation point

725 LVL

Liquid-vapour-liquid transition

$726 \mathrm{p}$

Plate

$727 \mathrm{r}$

Reverse mode

728 R

Radiative component

729 S

Structural element(s) such as internal support struts

730 ss

Between two adjacent struts (centre-to-centre distance)

731 sw

Strut tube wall (thickness)

732 sxy

Between the $x y$-sidewall and the closest strut (distance along the $z$-axis) 
Between the $x z$-sidewall and the closest strut (distance along the $y$-axis)

$734 \mathrm{~V}$

Working fluid vapour state property

735 w Sidewalls of the PLVTD

$736 \times$

In the direction parallel to the PLVTD depth

$737 y$

In the direction of the horizontal axis perpendicular to PLVTD depth

738 z

In the direction of the axis which is perpendicular to $x$ and $y$ axes

\section{References}

741 Avanessian, T. \& Hwang, G. (2018). Thermal diode using controlled capillary in heterogeneous

742 nanopores. International Journal of Heat and Mass Transfer 124 (2018) 201-209

743 Baïri, A., Zarco-Pernia, E., García de María, J. (2014). A review on natural convection in 744 enclosures for engineering applications. The particular case of the parallelogrammic diode

745 cavity. Applied Thermal Engineering 63 (2014) 304-322

746 Ben-Abdallah, P and Biehs, S. (2013). Phase-change radiative thermal diode. Applied Physics 747 Letters $103(19)$

748 Blet, N., Lips, S., Sartre, V. (2017). Heats pipes for temperature homogenization: A literature 749 review. Applied Thermal Engineering 118 (2017) 490-509

750 Boreyko, J. \& Chen, C. (2013). Vapor chambers with jumping-drop liquid return from 751 superhydrophobic condensers. International Journal of Heat and Mass Transfer 61 (2013) 409$752 \quad 418$

753 Boreyko, J., Zhao, Y., Chen, C. (2011). Planar jumping-drop thermal diodes. Applied Physics 754 Letters 99, 234105

755 Chen, K., Chailapo, P., Chun, W., Kim, S., Lee, K. (1998). The Dynamic Thermosiphon of a 756 bayonet-type thermal diode. Solar Energy 64 (4-6) 257-263

757 Chen (2012). Patent Application for Thermal Diode Device and Methods. US 2012/0012804 Al

758 Collins, R. \& Fischer-Cripps, A. (1991). Design of Support Pillar Arrays in Flat Evacuated 759 Windows. Australian Journal of Physics 1991 (44) 545-63

760 De Beijer, H. (1998). Product development in solar water heating. Renewable Energy 5 (1998) $761 \quad 201-204$

762 Dos Santos Bernardes, M. (2014). Experimental evidence of the working principle of thermal 763 diodes based on thermal stress and thermal contact conductance - Thermal semiconductors. 764 International Journal of Heat and Mass Transfer 73 (2014) 354-357

765 Dupeyrat, P., Menezo, C., Rommel, M., Henning, H. (2011). Efficient single glazed flat plate 766 photovoltaic-thermal hybrid collector for domestic hot water systems. Solar Energy 85, 1457-68 
Fang, Y., Hyde, T., Arya, F., Hewitt, N., Eames, P., Norton, B., Miller, S. (2014). Indium alloysealed vacuum glazing development and context. Renewable and Sustainable Energy Reviews 37 (2014) 480-501

770 Gaddam, P., Huxtable, S., Ducker, W. (2017). A liquid-state thermal diode. International 771 Journal of Heat and Mass Transfer 106 (2017) 741-744

772 Gerstmann, J. \& Griffith, P. (1967). Laminar Film Condensation on the Underside of Horizontal 773 and Inclined Surfaces. International Journal of Heat and Mass Transfer 10 (1967) 567-80.

774 Go, D. \& Sen, M. (2010). Thermal Rectification Using Bulk Materials. ASME Journal of Heat 775 Transfer $132(12) 124502$

776 Hess, T., Maier, L., Corhan, P., Schäfer-Welsen, O., Wöllenstein, J., Bartholomé, K. (2019). 777 Modelling cascaded caloric refrigeration systems that are based on thermal diodes or switches. 778 International Journal of Refrigeration 103 (2019) 215-222

779 Muhumuza, R., Zacharopoulos, A., Mondol, J., Smyth, M. (2019a). Experimental study of heat 780 retention performance of thermal diode Integrated Collector Storage Solar Water Heater 781 (ICSSWH) configurations. Sustainable Energy Technologies and Assessments 34 (2019) 214-219

782 Muhumuza, R., Zacharopoulos, A., Mondol, J., Smyth, M., Pugsley, A., Giuzio, G., Kurmis, D. 783 (2019b). Experimental investigation of horizontally operating thermal diode solar water heaters 784 with differing absorber materials under simulated conditions. Renewable Energy, Volume 138, 785 August 2019, Pages 1051-1064

786 NIST (2013). Standard Reference Database 23 Version 1. Gaithersburg, MD, USA: National 787 Institute of Standards and Technology (NIST) US Department of Commerce. (Accessed via 788 REFPROP software).

789 Pan, Y., Wu, C. Z. (2002). Numerical investigations and engineering applications on freezing 790 expansion of soil restrained two-phase closed thermosyphons. International Journal of Thermal 791 Sciences 41 (2002) 341-347

792 Pei, W., Zhang, M., Li, S., Lai, Y., Jin, L., Zhai, W., Yu, F., Lu, J. (2017). Geotemperature control 793 performance of two-phase closed thermosyphons in the shady and sunny slopes of an 794 embankment in a permafrost region. Applied Thermal Engineering 112 (2017) 986-998

795 Peterson, P. (1996). Theoretical basis for the Uchida correlation for condensation in reactor 796 containments. Nuclear Engineering and Design 162 (1996) 301-306.

797 Pugsley, A., Mondol, J., Smyth, M., Zacharopoulos, A. \& Di Mattia, L. (2016). Experimental 798 characterisation of a flat panel integrated collector-storage solar water heater featuring a 799 photovoltaic absorber and a planar liquid-vapour thermal diode. Proceedings of 11 th ISES 800 EuroSun Conference: Palma (Mallorca), Spain from 11 to 14 October 2016. Martinez, V. \& 801 Gonzalez, J. (eds.). 
802 Pugsley, A. (2017). Theoretical and experimental analysis of a novel flat photovoltaic-thermal 803 solar water heater with integrated energy storage via a planar liquid-vapour thermal diode. 804 Ulster University PhD Thesis (uk.bl.ethos.713462) published July 2017.

805 Quinlan, P. (2010). The Development of a Novel Integrated Collector Storage Solar Water 806 Heater (ICSSWH) Using Phase Change Materials and Partial Evacuation. PhD Thesis, University 807 of Ulster.

808 Reay, D., Kew, P., McGlen, R. (2014). Heat Pipes - Theory, Design and Applications (6th 809 edition). London, UK: Butterworth-Heinemann (Elsevier). ISBN: 0080982794

810 Roberts, N. \& Walker, D. (2011). A review of thermal rectification observations and models in 811 solid materials. International Journal of Thermal Sciences 50 (2011) 648-62.

812 Shen, J., Liu, X., He, H., Wu, W., Liu, B. (2018). High-performance noncontact thermal diode 813 via asymmetric nanostructures. Journal of Quantitative Spectroscopy \& Radiative Transfer $814211(2018) 1-8$

815 Smyth, M. (2015a). A solar water heater. Patent WO2010052010 held by Ulster University.

816 Smyth, M., Besheer, A., Zacharopoulos, A., Mondol, J., Pugsley, A., Novaes, M. (2015b). 817 Experimental evaluation of a Hybrid Photovoltaic/Solar Thermal (HyPV/T) Façade Module. 818 Proceedings EURO ELECS Conference 21-23 July 2015, Guimarães, Portugal.

819 Smyth, M., Quinlan, P., Mondol, J., Zacharopoulos, A., McLarnon, D., Pugsley, A. (2017). The 820 evolutionary thermal performance \& development of a novel thermal diode pre-heat solar water 821 heater under simulated heat flux conditions. Renewable Energy 113 (2017) 1160-1167

822 Smyth, M., Quinlan, P., Mondol, J., Zacharopoulos, A., McLarnon, D., Pugsley, A. (2018). The 823 experimental evaluation and improvements of a novel thermal diode pre-heat solar water 824 heater under simulated solar conditions. Renewable Energy 121 (2018) 116-122

825 Smyth, M., Pugsley, A., Hanna, G., Zacharopoulos, A., Besheer, A., Savvides, A. (2019). 826 Experimental performance characterisation of a Hybrid Photovoltaic/Solar Thermal Façade 827 module compared to a flat Integrated Collector Storage Solar Water Heater module. Renewable 828 Energy 137 (2019) 137-143

829 Souliotis, M., Quinlan, P., Smyth, M., Tripanagnostopoulos, Y., Zacharopoulos, A., Ramirez, M., 830 Yianoulis, P. (2011). Heat retaining integrated collector storage solar water heater with 831 asymmetric CPC reflector. Solar Energy 85 (2011) 2474-87

832 Souliotis, M., Papaefthimiou, S., Caouris, Y., Zacharopoulos, A., Quinlan, P., Smyth, M. (2017). 833 Integrated collector storage solar water heater under partial vacuum. Energy 139 (2017) 9918341002

835 Stein, R., Cho, D., Lambert, G. (1985). Condensation on the underside of a horizontal surface 836 in a closed vessel (CONF-850810-27). Argonne, Illinois, USA: Argonne National Laboratory. 837 Available at: www.osti.gov/scitech/biblio/5207060 
838 Traipattanakul, B., Tso, C., Chao, C. (2019). A phase-change thermal diode using electrostatic839 induced coalescing jumping droplets. International Journal of Heat and Mass Transfer 135 $840 \quad$ (2019) 294-304

841 Tso, C., Chao, C. (2016). Solid-state thermal diode with shape memory alloys. International 842 Journal of Heat and Mass Transfer 93 (2016) 605-611

843 Twidell, J. \& Weir, T. (2006). Renewable Energy Resources (2nd ed.) London: Taylor Francis. 844 ISBN13:9-78-0-419-25330-3

845 Varga, S., Oliveira, A., Afonso, C. (2002). Characterisation of thermal diode panels for use in 846 the cooling season in buildings. Energy and Buildings 34 (2002) 227-235

847 Villeneuve, T., Boudreau, M., Dumas, G. (2017). The thermal diode and insulating potentials of 848 a vertical stack of parallelogrammic air-filled enclosures. International Journal of Heat and Mass 849 Transfer 108 (2017) 2060-2071

850 Wong, M., Traipattanakul, B., Tso, C., Chao, C., Qiu, H. (2019). Experimental and theoretical 851 study of a water-vapor chamber thermal diode. International Journal of Heat and Mass Transfer 852138 (2019) 173-183 